\title{
La gestión de la institución educativa y su vínculo con la comunidad
}

\author{
Education management and their link with the community
}

Recibido 17 junio 2013 • Aceptado 26 junio 2013 • Corregido 28 junio 2013

\author{
Yadira Abarca Hernández' \\ Ministerio de Educación Pública, Costa Rica \\ yadiabarca@hotmail.com \\ Lizeth Aguilar Zumbado² \\ Ministerio de Educación Pública, Costa Rica \\ lazumbado@hotmail.com \\ María del Rosario Cambronero Oviedo ${ }^{3}$ \\ Ministerio de Educación Pública, Costa Rica \\ rosariocambronerooviedo@gmail.com \\ José Enrique Chavarría Chavarría \\ Ministerio de Educación Pública, Costa Rica \\ joseenrique2ch@gmail.com \\ Leonardo Fabio Moya Obando \\ Ministerio de Educación Pública, Costa Rica \\ leomoyao@hotmail.com \\ Juan Paulo Murillo Picado ${ }^{6}$ \\ Ministerio de Educación Pública, Costa Rica \\ paulomurillo@yahoo.ca
}

${ }^{1}$ Licenciada en Ciencias de la Educación con énfasis en Administración Educativa de la Universidad de Costa Rica (UCR). Bachiller en Ciencias de la Educación de la Universidad de Costa Rica (UCR). Labora como profesora para el Ministerio de Educación Pública (MEP).

2 Licenciada en Ciencias de la Educación con énfasis en Administración Educativa de la Universidad de Costa Rica (UCR). Bachiller en Ciencias de la Educación de la Universidad de Costa Rica (UCR). Labora como profesora para el Ministerio de Educación Pública (MEP).

${ }^{3}$ Licenciada en Ciencias de la Educación con énfasis en Administración Educativa de la Universidad de Costa Rica (UCR). Bachiller en Ciencias de la Educación de la Universidad de Costa Rica (UCR). Labora como profesora para el Ministerio de Educación Pública (MEP).

${ }^{4}$ Licenciado en Ciencias de la Educación con énfasis en Administración de la Educación de la Universidad de Costa Rica (UCR). Bachiller en Ciencias de la Educación de la Universidad de Costa Rica (UCR). Labora como profesor para el Ministerio de Educación Pública (MEP).

5 Licenciado en Ciencias de la Educación con énfasis en Administración de la Educación de la Universidad de Costa Rica (UCR). Bachiller en Enseñanza del Inglés de la Universidad de Costa Rica (UCR). Labora como profesor de inglés para el Ministerio de Educación Pública (MEP) y para el Colegio Universitario de Cartago (CUC).

${ }^{6}$ Licenciado en Ciencias de la Educación con énfasis en Administración de la Educación de la Universidad de Costa Rica (UCR). Bachiller en Enseñanza del Inglés de la Universidad de Costa Rica (UCR). Labora como profesora para el Ministerio de Educación Pública (MEP). 
Resumen. Con el propósito de profundizar en la compleja y transcendental relación entre la gestión de la educación y el vínculo con la comunidad, se propuso el presente estudio como objetivo a analizar la gestión de los centros educativos Unidad Pedagógica Rafael Hernández Madriz, Escuela Santiago Crespo Calvo, Liceo Nocturno de Ciudad Colón, Colegio San José de la Montaña y Liceo Ambientalista de Horquetas, con respecto al vínculo con la comunidad del contexto educativo. Se seleccionaron diferentes centros educativos que pertenecen a contextos comunales distintos y poder ofrecer con mayor amplitud, mediante un estudio cualitativo, los alcances que la gestión de la educación conlleva con respecto a las relaciones que se estructuran con su comunidad para lograr los objetivos institucionales. Dentro de las conclusiones del estudio del resalta la importancia de la gestión de la educación con la comunidad a la cual pertenece en el logro de los objetivos educativos.

Palabras claves. Administración de la Educación, Gestión de la Educación, Institución Educativa y Vínculo con la Comunidad, Contexto Comunal, Gestión de la Educación y Comunidad, Comunidad Educativa

Abstract. With the purpose of deepening in the transcendental complex relationship between education management and the link with the community, this study proposed as objective analyze the management of Rafael Hernández Madriz school and Santiago Crespo Calvo School, Liceo Nocturno de Ciudad Colon, San Jose de la Montaña High School, and Liceo Ambientalista de Horquetas with respect to the link with the community of the educational context. Different schools were selected belonging to different communal contexts and offer more widely through a qualitative study the scopes that management of education involves regarding the relationships with their community to achieve institutional goals. Among the findings of the study emphasizes the importance of the management of education with the community to which it belongs in the achievement of the educational objectives.

Keywords. Educational Administration, Educational Management, Educational Institution and Link with the Community, Community Context, Management and Community Education, Community.

\section{Contextualización}

La sociedad enfrenta distintos cambios tecnológicos, políticos, sociales y económicos que afectan de manera directa al sistema educativo. Por ejemplo, el avance tecnológico crece de manera acelerada, esto promueve que las personas cambien sus comportamientos sociales. En relación con el tema, De Alba citada por Gurdián (2000) aclara que el cambio tecnológico es un elemento que forma parte de las nuevas formas de estructuración social, de los espacios sociales, de la inclusión o exclusión social.

El sistema educativo y los gestores de la educación deben encargarse de la resolución de problemas y la adaptabilidad de la institución educativa para el enfrentamiento de estos cambios. Al respecto, Pérez citada por Gurdián (2000) explica que la escuela y la familia 
son agentes socializadores que buscan el objetivo de formar a la persona, pero ambos se acusan de los fallos en el sistema educativo. De ahí que, la participación activa de padres en la escuela y en el hogar ha demostrado ser un factor influyente en el aprovechamiento académico, la asistencia, la tasa de retención y la graduación de los estudiantes.

Por otra parte, Coleman (1998) y Rubin (2002) citados por Medina (2011) sugieren que es necesario que los padres, maestros, administradores, miembros de la comunidad y estudiantes trabajen en colaboración para crear en la escuela una comunidad de aprendizaje exitosa. La cooperación en un escenario educativo no sólo es una forma de resolver los problemas, sino que se considera el componente esencial para su efectividad.

\section{Justificación e importancia del tema}

La relación entre la gestión de una organización educativa y la comunidad es un tema de importancia para lograr los fines primordiales de la educación, entre los cuales cabe destacar el inciso c) del artículo $2^{\circ}$ de la Ley Fundamental de Educación (2003) № 2160 de 1957: "Formar ciudadanos para una democracia en que se concilien los intereses del individuo con los de la comunidad" (p. 119). Al respecto, es evidente la responsabilidad inmediata del personal directivo de velar porque este fin de la educación costarricense sea cumplido dentro de la labor y hay más posibilidades de lograrlo cuando se involucra a la comunidad del contexto educativo.

Una organización educativa, se encuentra dentro de un complejo sistema social; al respecto, Lejtman (1996) citado por García, Rojas y Campos (2002), explica que "la escuela como institución integral requiere una visión comprensiva un abordaje totalizador, una relación dialéctica entre procesos y resultados, de la que es responsable quien o quienes ejerzan la conducción general" (p. 2). Por lo tanto, la dirección debe propiciar que este vínculo entre la organización educativa y la comunidad sea el más adecuado para desarrollar la tarea principal que es la de formar mejores ciudadanos.

Además, a través de todas estas estrategias el director debe mantener un equilibrio social entre el contexto comunal y su centro. Al respecto, Tejada (2000) afirma que la educación exige una adaptación al contexto "cultural, social, laboral, profesional y personalmente" (p. 1). De esta forma surge el interés de plantearse los siguientes objetivos de investigación: 


\section{Objetivo general}

- Analizar la gestión de los centros educativos Unidad Pedagógica Rafael Hernández Madriz, Escuela Santiago Crespo Calvo, Liceo Nocturno de Ciudad Colón, Colegio San José de la Montaña y Liceo Ambientalista de Horquetas, con respecto del vínculo con la comunidad del contexto educativo.

\section{Objetivos específicos.}

- Identificar en la planificación institucional de los centros educativos los criterios por considerar para la articulación del proyecto educativo y la comunidad.

- Describir el proceso de organización que es implementando para las instituciones educativas para vincular a la comunidad.

- Identificar las estrategias de dirección implementadas en las organizaciones educativas para vincular el centro educativo y la comunidad.

- Determinar los mecanismos de coordinación empleados entre las organizaciones educativas para la vinculación comunal.

- Reconocer los criterios de control empleados en las instituciones educativas para la ejecución del proyecto institucional y la articulación con la comunidad.

- Describir los métodos de evaluación empleados en las organizaciones educativas con respecto de la ejecución del plan institucional y la vinculación la comunidad.

La investigación sobre la gestión de la institución educativa y el vínculo con la comunidad se desarrolló en la siguientes instituciones educativas: Unidad Pedagógica Rafael Hernández Madriz, Escuela Santiago Crespo Calvo, Liceo Nocturno de Ciudad Colón, Colegio San José de la Montaña y Liceo Ambientalista de Horquetas, instituciones educativas públicas con características particulares y contextos diferentes, con el fin de realizar una comparación e indagar los distintos factores que intervienen en la relación escuela-comunidad. A continuación, se presenta una contextualización de estas instituciones.

\section{Referentes teóricos}

\section{Teoría de la educación}

Al ser la educación un instrumento primordial en el desarrollo de la sociedad, general e integral del ser humano, se hace necesario definir algunos términos para comprender, en 
forma adecuada, el mismo. Uno de estos conceptos es el de Fermoso (1985) citado por Paciano, Cappella y Collom (2005), quien aclara que la teoría de la educación es la fundamentación de la práctica educativa, justifica la teoría de las actividades prácticas del proceso educativo y dice qué se debe hacer.

Meza (1999) especifica que la palabra educación es un vocablo latino, proviene de educare que significa alimentar, criar, nutrir y ex ducere que significa desarrollar o crecer. Por lo que el término educación hace referencia al proceso en el cual distintos seres humanos entran en relación y se generan ciertos cambios en el interior de cada uno de ellos.

Al igual, toda actividad educativa tiene una consecuencia social, la misión de la educación es la promoción de la superación de las condiciones de desigualdad, porque es una fuerza homogeneizadora, que refuerza y promueve la cohesión social y garantiza la integración social (Morales, 2004). Al ser la educación y la instrucción procesos de carácter humano que generan el desarrollo de una sociedad y acciones realizadas y recibidas por la persona, cuya influencia positiva o negativa recae sobre sí misma, como parte de una comunidad que busca la plenitud personal; Barrantes (2000) explica que la educación formal es un tema de recurrente discusión social, en un momento en que la sociedad experimenta cambios profundos en los planos sociales, culturales, políticos.

Es así como a la instrucción se le atribuye ser una herramienta utilitaria para la concepción político-ideológica de los pueblos y tiene como objeto básico transmitir a la persona en formación y en continua transformación del pensamiento. Así mismo, como anota Meza (1999) "el concepto de educación difiere del concepto de instrucción en el sentido de que instrucción se refiere a la transmisión de conocimientos e información específica, en tanto que la educación abarca la formación integral del individuo" (p.12).

Dados los aportes anteriores, se infiere la diferencia que existe entre educar e informar, concepción clara de que la instrucción, en la mayoría de las ocasiones, entrega datos que tienen poca o nada de notabilidad y no transfiere experiencias de aprendizajes significativos y constructores de un evidente pensamiento crítico, analítico y creativo. Freire (2004) aclara que enseñar exige varias características, entre ellas: metodología, investigación, respeto, crítica, estética, ética, reflexión y reconocimiento de la diversidad cultural.

Es necesario que los educadores y los administradores de la educación, como entes promotores de estos procesos y facilitadores activos del desarrollo personal y social, reflexionen sobre estos conceptos y su relación directa sobre los objetivos que postula la escuela, como institución formadora de una ciudadanía presente y futura y el papel que desempeña la misma en la formación permanente del ser humano. Al respecto, Meza (1999) aclara que el término educación hace referencia a los principios de individualización, socialización, autonomía, 
actividad y creatividad, mismos que permitirán diferenciar las personas, relacionarlas con la sociedad, respetar su libertad, actuar con inteligencia y aprovechar su producción. Para Freire (2004) la práctica educativa no es una experiencia sin el sentido humano, que toma en cuenta "los sentimientos y las emociones, los deseos, los sueños" (p. 44).

Avolio (1980) especifica que la educación supone un fin que se debe alcanzar, es un estado diferente al que se tenía originalmente, por lo que el sujeto tiende a lograr un deber ser que es el fin de la educación.

\section{Teoría de la administración}

La palabra administración procede del latín ad (hacia, dirección, tendencia) y minister (subordinación u obediencia) y significa aquel que realiza una función bajo el mando de otro, es decir, aquel que presta un servicio a otro; sin embargo, la tarea de la administración pasó a ser la interpretación de los objetivos propuestos por la organización y transformados en acción organizacional a través de la planeación, la organización, la dirección y el control de todos los esfuerzos realizados en todas las áreas y en todos los niveles de la organización, con el fin de alcanzar tales objetivos de la manera más adecuada a la situación y garantizar la competitividad en un mundo muy competitivo y complejo (Chiavenato, 2004).

El concepto de administración contempla una serie de elementos que se deben tomar en cuenta en el momento de su conceptualización y aplicación. Los cuales son:

a. Planeación: avizorar el futuro y trazar el programa de acción, por lo que Gairín y Darder

(1994) anotan que es un proceso ordenado, duradero y accesible que sirve para aplicar a la educación. El concepto de planeación se utiliza para una anticipación del futuro, la imprevisión de lo que pueda suceder, el proceso continuo y unitario, la formulación de decisiones, la ejecución de un plan, el proceso de reflexión, la dimensión ideológica consecuencias subjetivas y debe ser integral que tome en cuenta las consideraciones y variaciones necesarias que imponga el tiempo.

b. Organización: se conceptualiza como la construcción de las estructuras material y social de la empresa. La organización es el proceso administrativo que da orden y secuencia a las acciones que se llevan a cabo para realizar un diagnóstico, forma parte de un plan, que ayuda a que las actividades que se ejecuten estén revisadas y controladas (Chaves, 1996).

c. Dirección: se define como la forma de guiar y orientar a la persona. La dirección es una de las funciones administrativas, que consiste en administrar las actividades de otras personas, motivar a todas las partes involucradas, escoger los canales de comunicación más eficaces y resolver conflictos surgidos entre los miembros de la fuerza de trabajo, Robbins y Coulter (2000). Implica mandar, influir y motivar a los empleados para que 
realicen tareas esenciales, las relaciones y el tiempo son fundamentales para las actividades de la dirección. Los gerentes dirigen tratando de convencer a los demás de que se les unan para lograr el futuro que surge de los pasos de la planificación y la organización. Los gerentes, al establecer el ambiente adecuado, ayudan a sus empleados a hacer su mejor esfuerzo (Stoner, Freeman y Gilbert, 1996).

d. Coordinación: enlaza, une y armoniza todos los actos y esfuerzos colectivos. Chiavenato (2003) define coordinación como:

El proceso que consiste en integrar las actividades de departamentos independientes a efectos de perseguir las metas de la organización con eficacia. El grado de coordinación dependerá de la naturaleza de las tareas realizadas y del grado de interdependencia que existe entre las personas de las diversas unidades que las realizan. (p. 22)

e. Control: verifica que todo suceda de acuerdo con las reglas establecidas y órdenes dadas. El control se puede definir de acuerdo con Munch y García (1986) como el verificar si todo ocurre de conformidad con el plan adoptado, con las instrucciones emitidas y con los principios establecidos, el proceso de medir los actuales resultados en relación con los planes; el proceso para determinar lo que se está llevando a cabo, valorización y, si es necesario, aplicando medidas correctivas, de manera que la ejecución se desarrolle de acuerdo con lo planeado e implica la medición de lo logrado en relación con lo estándar y la corrección de las desviaciones.

f. Evaluación: la evaluación es el proceso de análisis estructurado y reflexivo, que permite entender la naturaleza del objeto de estudio y emitir juicios de valor sobre el mismo, proporciona información para auxiliar y ajustar la acción educativa (Ruiz, 2008, citado por Campos, 2011). En este aspecto, la gestión educativa debe considerar una cultura de evaluación institucional, como base central para alcanzar mejoras institucionales u organizacionales, en donde la intervención de la comunidad es importante. La evaluación permite definir, obtener y proporcionar información necesaria para juzgar alternativas en una decisión (Stufflebeam citado por Bolaños y Navas, 2004).

\section{Teoría de la administración de la educación}

La administración de la educación es un proceso de trabajo organizado, que está inmerso en el desarrollo de las instituciones educativas, con una visión a futuro, para alcanzar los fines y objetivos que rigen la educación. Para Garbanzo y Orozco (2007), la administración de la educación se sustenta holísticamente en disciplinas como las ciencias de la educación, la teoría administrativa, la psicología, la sociología, la economía, el derecho, las ciencias políticas, etc., lo que permite la acción en varios contextos sociales. 
La administración de la educación debe preocuparse constantemente por satisfacer las necesidades y las expectativas sociales; por ello, la administración y la educación no son disciplinas aisladas, dentro de las instituciones escolares se complementan; de ahí que las personas encargadas de la administración requieren estar preparadas en las funciones de planificación, organización, control y comportamiento humano, es imprescindible que sean hábiles en las distintas formas de administrar las operaciones institucionales. Al mismo tiempo, deben ser líderes que aprendan de las escuelas, que confíen en la colectividad y confíen en sí mismo (García y Rojas, 2002, citado por García, Rojas y Campos, 2002).

Es indispensable que se destaque el sentido de liderazgo democrático, como persona planificadora, animadora de los procesos de auto y mutua capacitación. Venegas (2002) citado por García, Rojas y Campos (2002) aclara que el administrador de la educación debe concebir al centro educativo como un lugar donde se inician los cambios y que no está esperando directrices del MEP, mediante una dirección participativa y democrática.

La administración de la educación como disciplina no se debe a sí misma, sino a una sociedad específica, con ciertas necesidades y retos, por lo que se acompaña de un modelo administrativo que concuerda con las propuestas curriculares del enfoque educativo (Garbanzo y Orozco, 2007). De esta forma, el sistema educativo, como parte del impulso social de un pueblo, representa una alternativa para los países en desarrollo.

Parte de las funciones de la persona encargada de la administración de un centro educativo es garantizar que se cumplan los fines de la educación, la administración del currículum y la toma de decisiones de los actores involucrados en el proceso educativo; para esto es necesario analizar las fortalezas, las debilidades, las amenazas y las oportunidades de la institución y tomar en cuenta cada una de las funciones, que según Escarrá (2002) citado por García, Rojas y Campos (2002) son planificación, dirección, organización, y evaluación.

De esta manera, la administración de la educación se percibe y desarrolla de manera holística, con una ética basada en el ejercicio responsable de los deberes y los derechos laborales; además, de la capacidad de asumir el riesgo en forma permanente, de una despolitización del debate educativo, de adecuados procesos de control de calidad, de promoción de la participación de la comunidad, del posicionamiento de la autonomía organizacional, de adecuados procesos de comunicación y toma de decisiones entre las estructuras involucradas (Garbanzo y Orozco, 2007).

Aunado a lo anterior, la administración de la educación se encarga de gestionar las prácticas pedagógicas que contribuyan con la transformación social e individual. Garbanzo y Orozco (2007) exponen que la administración de la educación, desde un enfoque de competitividad, debe estar en correspondencia con los requerimientos sociales y económicos de un país; 
por lo que es necesario la articulación de estrategias y políticas educativas en conjunto con las políticas del estado, a partir de un enfoque de equidad social, de esta manera el sistema educativo contribuye a producir el capital humano requerido.

\section{Gestión de la educación}

La relación escuela-comunidad debe considerar la definición de gestión, misma que "se relaciona en la literatura especializada como management y este es un término de origen anglosajón que suele traducirse al castellano como dirección, organización, gerencia" (Pozner, 2000, p. 16). Existen términos propios de gestión que contribuyen a delimitar el concepto de gestión de la educación, entre ellos: piloteo de organizaciones, innovación, exploración, mejora continua, profesionalización de las acciones educativas, identificación de fortalezas y dificultades, pensamiento útil para la acción, reflexión para la decisión, liderazgo pedagógico, visión de futuro, comunicación y aprendizaje, estrategias, punto de apalancamiento, construcción de redes (Fernández, 2000).

Casassus (2000) citado por Venegas (2011) explica que la gestión es un concepto más genérico que administración, porque va mucho más allá de la ejecución de instrucciones, de manera que gestión implica las acciones de planificar y las de administrar. En este contexto, la gestión educativa es un conjunto de procesos teóricos y prácticos dentro del sistema educativo, para cumplir ciertos mandatos formales, en donde se evidencia una nueva forma de comprender y conducir la organización escolar.

Chacón (2012) aclara que la gestión de la educación debe centralizarse en el fomento de la autonomía (institucional e individual), en la resolución de las diversas situaciones que se presenten a lo interno como a lo externo de la organización; en el fomento de la democracia, (la participación e información de los procesos de toma de decisiones institucionales), y la participación de cada uno de los miembros de la comunidad educativa.

Dado el conocimiento, deja de ser lento y estable; Hopenhayn (2002), Tejada (2000), Amar (2000) y Buendía y Martínez (2007) hacen referencia a que quienes están al frente de las organizaciones educativas deben ser partícipes de las respuestas a las actuales demandas de la sociedad, donde se tome en cuenta la internacionalización de la educación, el bajo costo en los sistemas educativos, la realización de acreditaciones de las carreras, programas y cursos, la atención a la mundialización, a la individualidad y a la competitividad, la contextualización de la enseñanza, la apertura de nuevos espacios de aprendizaje, recursos y medios para superar las tecnologías tradicionales de enseñanza y la investigación en nuevos principios educativos y bases curriculares. 
Aunado a lo anterior, se debe tomar en cuenta que una organización educativa no debe ser dirigida como cualquier empresa, ya que es una organización pedagógica con un proyecto social implícito (Garbanzo y Orozco, 2007). Así, la gerencia participativa y la promoción social son aspectos importantes en una institución escolar, por la naturaleza de las funciones en beneficio de la sociedad.

Autores como Garbanzo y Orozco (2010) consideran que los componentes fundamentales de un modelo de gestión educativa competitiva son: la centralización en lo pedagógico, las nuevas competencias y la profesionalización, el trabajo en equipo, la cultura organizacional con visión de futuro, la apertura al aprendizaje y a la innovación, el asesoramiento y la profesionalización

Los elementos anteriormente nombrados requieren el cumplimiento de las funciones directivas de la administración de la educación: analizar y sintetizar, anticipar y proyectar, concertar y asociar, decidir y desarrollar, comunicar y coordinar, liderar y animar, evaluar y reenfocar; y como consecuencia, el ejercicio profesional en el campo de la administración de la educación requiere un enfoque claro e interrelacionado, alta capacidad de concentración, conciencia de que los tiempos de gestión suponen períodos prolongados, investigación permanente de las oportunidades, capacidad de experimentar, disciplina para el aprendizaje profundo, satisfacción por el riesgo, confianza en sí mismo, sentido de la responsabilidad, saber aprender, compromiso e iniciativa, saberes y prácticas de colaboración, profesionalidad y voluntad de servicio (Garbanzo y Orozco, 2010).

Uno de los aspectos más destacados en la gestión de la administración es la motivación, misma que contiene entusiasmo por el trabajo. El entusiasmo es un impulso interno que produce ánimo y orientación, por lo tanto, es necesario que exista motivación, misma que debe ser de buena gana y no a la fuerza, la función del administrador es la de descubrir cómo las diferentes personas responden a una clase de trabajo, si actúan por sí mismos, motivados, a conciencia (Belker y Topchik, 2005).

Al respecto, existe coincidencia con Stoner, Freeman y Gilbert (1996) al definir liderazgo como un proceso natural de influencia interpersonal que lleva al individuo y al grupo a formar lo que el líder quiere que hagan. Pero de total acuerdo y entusiasmo con el equipo de trabajo, por lo que la influencia se evidencia como "cualquier acto o ejemplo de conducta que ocasiona un cambio en la actitud o la conducta de otra persona o grupo" (p. 514). El profesional en gestión de la educación debe transformarse dentro de la comunidad en un actor que empuje con entusiasmo y liderazgo la participación de los diferentes miembros de la comunidad. 


\section{Las organizaciones educativas}

Toda organización educativa es una realidad concreta, donde el contexto comunal es parte de ella, que de manera tradicional, es vista como una distribución de tareas que siguen unas líneas jerárquicas y burocráticas. Esta perspectiva limita la intervención del profesorado en la organización de su trabajo y se reproduce la separación entre los que planifican, y ejecutan, entre los que evalúan y enseñan.

Las organizaciones escolares son parte de un sistema social más amplio y sus estructuras internas se ven afectadas por los entornos sociales de muy variadas maneras. Los centros educativos no existen como realidades individuales y al margen de los sistemas sociales, culturales, profesionales, políticos, artísticos o económicos (González, 2003). La educación se ha ido haciendo más complicada, técnica, social y políticamente, requiere de estructuras también más complejas.

Equipos docentes, departamentos, coordinadores, comisiones de trabajo, todos estos sistemas de organización son, en realidad, la esencia de una institución pensada para la enseñanza. González (2003) comenta que las dimensiones constitutivas de la organización escolar son la estructura organizativa formal, las relaciones entre los individuos que la componen, los supuestos, los valores y las creencias organizativas, los procesos y las estrategias de actuación a través de las cuales la organización funciona y se relaciona con el entorno.

\section{La familia}

La familia es la base de cada comunidad. Está compuesta por individuos como los padres, los hijos y los hermanos. Se dice que la familia es la unidad básica de toda sociedad, ahí empiezan la educación y las buenas costumbres y se encarga de socorrer, ayudar y proporcionar la satisfacción de las necesidades básicas a sus integrantes. Es en ella donde las personas nacen, crecen y se desenvuelven, aprenden valores, respeto por sí mismos y por los demás; desarrollan capacidad para tomar decisiones y para ser responsables (Álvarez, 1996).

Para Salas (2002) citada por García, Rojas y Campos (2002), la familia por sus orígenes y funciones, es fundamental en el proceso educativo humano, ya que es la primera instancia social encargada de dar las bases de socialización necesarias para el desarrollo de la vida en común y del trabajo a los miembros infantiles. De esa manera, la familia es educadora nata y primaria, fomenta un clima que facilita y asegura la educación integral, posee una función educadora vital para el ser humano, pues el ambiente más cercano para él es el de su hogar, del cual adquiere muchas experiencias y pautas para seguir (Mora y Solano, 2005). Ella transmite la vida a sus hijos y comunica la idiosincrasia del grupo social al que pertenecen y el patrimonio cultural del pueblo. 


\section{Los docentes}

La presencia y la labor del docente siempre han sido respetadas y llenas de credibilidad dentro de la comunidad educativa, aun cuando ello se cuestione hoy. El profesor ha estado investido de cierto grado de liderazgo y autoridad en su comunidad, lo cual también está mermando. Freire (1990) expresa que: "el rol del educador consiste en proponer problemas en torno a situaciones existenciales codificadas para ayudar a los educandos a alcanzar una visión cada vez más crítica de su realidad" (p. 75).

Es importante replantearse las nuevas demandas sociales, culturales y profesionales que el entorno le exige al docente actual, es necesario tomar en cuenta lo que Garbanzo (2011) explica, el docente requiere desarrollar competencias para trabajar en redes de comunidades, donde la barrera del centro educativo sea superada por una acción en una sociedad integrada, debe trabajar de forma interconectada y apropiarse de las tecnologías de la información y la comunicación como herramienta útil, con sentido ético en su actuar y dispuesto a incursionar en los cambios requeridos de forma inmediata y adquirir una actitud hacia el crecimiento profesional y la actualización.

\section{Los estudiantes}

Es el elemento primordial del proceso, por quien surge el sistema y se mantiene, por ellos surgen cambios novedosos, es así como lo define Dengo (2000) cuando aclara que los procesos educativos son encausados a cubrir las necesidades del alumnado.

Para Freire (2004) cuando un verdadero aprendizaje se logra, los alumnos se van "transformando", al igual que el educador, en personas que construyen y reconstruyen la enseñanza.

El Consejo Nacional de Rectores (CONARE, 2011) explica que los educandos son los principales actores de la comunidad educativa, "a ellos se debe el sistema y por ellos está obligado a mejorar" (p. 118). En este aspecto, se nota que los sistemas educativos liderados por la administración de la educación están obligados a mejorar, a actualizarse y a procurar los mejores procedimientos organizacionales para el beneficio de la comunidad estudiantil.

El profesional en administración de la educación

Un administrador de la educación en la escuela contemporánea es un profesional con rasgos de líder, un facilitador, alguien que cree en los demás, percibe que los otros tienen la capacidad de realizar acciones con iniciativa propia, cree en la responsabilidad y en 
los constantes procesos de maduración; su comunicación es directa con los diferentes miembros del sistema educativo (administrador, asesores, supervisores, estudiantes, padres de familia, jefes administrativos, dirigentes comunales, comunidad en general) (Venegas, 2000).

\section{La comunidad y comunidad educativa}

Seconsidera el concepto de comunidad educativa, como el espacio físico, social y cognitivoafectivo que se especifica en la naturaleza de las relaciones educativas que se establecen o se instituirán, entre los distintos individuos, grupos o sectores que concurren en el centro escolar, como agentes interventores facilitadores del proceso de formación (Álvarez, 2009). Por lo que es propio del administrador de la educación, proporcionar acciones que circunscriban a todos los integrantes de la comunidad educativa, de modo que se puedan determinar factores sociales, económicos, educativos, aptitudes, intereses, limitaciones, entre otros. La comunidad educativa es muy compleja, misma que se define como la que se encuentra conformada por estudiantes, educadores, padres de familia o encargados de los estudiantes, egresados, directivos, directivos y docentes administrativos escolares (Ordoñez, 2002).

\section{Relación del contexto social, la comunidad y la organización educativa}

Las organizaciones educativas, a criterio de Garbanzo y Orozco (2010), son los espacios donde se sintetiza el proceso enseñanza-aprendizaje que despliega las capacidades cognitivas del alumnado y potencializa la formación integral (ética, estética, cultural y espiritual). Así, no es posible explicar la escuela sin tomar en cuenta su contexto social, cultural, económico y político. Evidentemente, el sistema educativo debe tener como referente el contexto sociocultural, si desea desarrollar una educación de calidad, donde tome en cuenta: la adaptación al contexto tanto de la comunidad como en general, la evolución de los conocimientos científicos, las nuevas tecnologías de la información y los cambios en las formas de vida y de trabajo.

Existen múltiples desafíos que motivan el pensamiento de que la educación contribuye a mejorar la calidad de vida de los seres humanos; para que la anterior meta se logre, es imprescindible un adecuado enlace del contexto social, la comunidad y la organización educativa.

Se compenetran cuatro situaciones que generan implicaciones en la respuesta educativa a nivel mundial, nacional y comunal: la globalización, el multiculturalismo, la revolución tecnológica y la incertidumbre valorativa. Estos factores deben tomarse en cuenta en el momento de plantear un cambio educativo que repercuta en la comunidad; porque en la escuela actual, la ausencia de referentes y valores deja un déficit de socialización, lo cual conlleva resultados en el estudiante (Tejada, 2000). 
Las organizaciones educativas son básicamente coaliciones compuestas por una diversidad de individuos y grupos de interés, como niveles jerárquicos, departamentos, grupos profesionales y hasta grupos raciales.

\section{Planificación institucional en las organizaciones educativas}

La planificación en el campo de las organizaciones educativas, dentro de su desarrollo teórico y operativo, toma en cuenta diversas áreas, como el componente social y económico de una región en particular, un contexto nacional determinado en el que operan las distintas organizaciones educativas. La planificación conceptualmente ha sido definida por diferentes autores, prevalece en sus distintos enfoques su papel en la capacidad de prever y tomar decisiones en aras del desarrollo organizacional, regional o nacional según los distintos objetivos a los cuales responde. Martín (2002), define la planificación como:

un instrumento de previsión y cambio que sirva como elemento para prever y proponer caminos de actuación, a la vez que selecciona y ordena los recursos, para facilitar el logro de las metas propuestas. La planificación responde a modelos siempre cambiantes, como lo son también las organizaciones, los centros escolares; la planificación constituye en sí misma un proceso que lleva a su modificación permanente, para así estar adaptada a la realidad en que actúa. (p. 23)

La educación en Costa Rica, presenta los diferentes desafíos a los que se enfrenta en forma constante, por ejemplo, pareciera haber un vacío en diferentes campos, entre ellos la planificación institucional, la cual se ve afectada por diferentes razones a nivel del centro educativo, como el impacto que diferentes programas y lineamientos educativos poseen sobre la planificación institucional, al respecto se destacan las Normas de Promoción y Repitencia del Reglamento de Evaluación de Aprendizajes del Ministerio de Educación Pública (MEP, 2011) que generan problemas como la sobrepoblación en ciertas materias y esto afecta el desarrollo organizacional. Una adecuada planificación, facilita en las organizaciones educativas la solución de los retos de una sociedad cada vez más exigente, con muchos cambios en su cultura, producto de la globalización, donde hay más diversidad multicultural. CONARE (2011) hace referencia a estas debilidades, deja claro la necesidad de que los estudiantes asistan a clases.

Según Chiavenato (2003), el FODA es un instrumento de planificación estratégica, que facilita la exploración del entorno, identifica los factores externos que deben ser previstos, y los factores internos (fortalezas y debilidades) que necesitan ser planificadas en la determinación de que una empresa debe ir en el futuro.

\section{Marco metodológico}

La naturaleza metodológica que se utilizó en esta investigación es cualitativa, de manera 
que permitiera conocer en este caso sobre la gestión que llevan a cabo los centros educativos en estudio con respecto de la vinculación del contexto comunal. La metodología cualitativa individualiza al sujeto investigado, no lo somete a categorías preconcebidas, se investiga un caso particular de un sujeto determinado y un contexto preciso, se construye la especificidad del sujeto como un momento concreto del desarrollo del conocimiento (Dornyei, 2007).

La población de este estudio está conformada por los administradores de la educación de las organizaciones escolares investigadas, los coordinadores académicos de los diferentes niveles, los presidentes de las juntas administrativas, de los patronatos escolares y de las juntas de educación, así como los supervisores de los circuitos educativos donde se localizan las instituciones participantes.

Las instituciones educativas se seleccionaron por distintas características, en cuanto a la modalidad académica que se desarrolla en la organización educativa, la población estudiantil y la diferencia de los contextos geográficos donde se ubican. Por la naturaleza del estudio y por la cantidad de sujetos no se tomó muestra, sino que se consideró la totalidad de los sujetos involucrados, lo cual se resume en la siguiente tabla:

En esta investigación, con base en los objetivos específicos planteados, se definieron las siguientes categorías de análisis:

- Planificación institucional - vinculación con la comunidad

- Proceso de organización - vinculación comunal

- Estrategias de dirección - vinculación comunal

- Mecanismos de coordinación - vinculación comunal

- Criterios de control- articulación con la comunidad

- Métodos de evaluación - vinculación con la comunidad

\section{Sistematización y análisis de la información}

Planificación institucional de los centros educativos y la articulación del proyecto educativo y comunidad.

En relación con los hallazgos y la participación de todos los integrantes en la definición y ejecución del plan institucional en los centros educativos para vincularlos con la comunidad, la mayoría de los entrevistados externaron que se realiza un diagnóstico de la comunidad para lograr la elaboración del plan anual institucional, el cual debe involucrar la opinión tanto de docentes como de padres de familia, situación que en los centros educativos en estudio se da 
de esta forma; principios de la planificación que coinciden con Gairín y Darder (1994), cuando expresan que es algo más que las simples expectativas del director sobre la evolución que seguirán los factores internos y externos de la institución en un plazo de tiempo determinado.

También se consideró importante que los planes deben tomar en cuenta tanto las fortalezas como debilidades de la institución para alcanzar el abordaje de las mismas, vincular y dar soluciones viables a la comunidad desde perspectiva social. Cabe destacar que los entrevistados concuerdan que las metas de la investigación deben ir dirigidas en la proyección de estas hacia la comunidad educativa y en general hacia la sociedad, pues la buena gestión de una organización educativa va a procurar una buena movilidad social de sus ciudadanos y para lograr esto los directores deben considerar todos los elementos de la comunidad.

Como se demuestra, la planificación de una institución debe basarse en la misión, visión y objetivos de la misma para logra salir adelante en la puesta en marcha de sus metas y alcances, lo cual se tiene claro en las instituciones participantes en la investigación, pues todos los entrevistados coinciden en la opinión de mantener estos elementos dentro de la creación de su plan de trabajo.

Sin embargo, en el momento de llegar a la programación de la puesta en marcha de dicho plan institucional, se encuentran algunas inconsistencias, pues aunque tienen claro los elementos al momento de planear para llevar su ejecución no tanto.

Para ilustrar esto, uno de los presidentes de junta administrativa comenta: la programación de ejecución no se incluye porque el tiempo asignadonoes suficiente. No hay canales de comunicación con la comunidad ni interés de ésta. El tiempo se consume en burocracia, con lo que se establece el organismo de apoyo.

Como se menciona, no existen canales de comunicación para articular la comunidad con la ejecución del plan y además suman el proceso burocrático como un factor entorpecedor para la eficiente articulación de la comunidad con la institución educativa. En lo que respecta al punto de vista de los miembros de los organismos de apoyo, la mayoría coincide con que la única acción de ejecución del plan por parte de ellos el desarrollo de las reuniones que tienen para la toma de decisiones que involucra la institución educativa.

Para el alcance de los objetivos planificados se han mencionada los comités encargados de distintas actividades propuestas. Uno de los coordinadores de primaria expresa: se realiza que cada comité formule un proyecto y se adjunta al plan.

La planificación debe considerar el tiempo, el espacio y los recursos con los cuales se llevara a cabo dicho proceso. Lo cual es confirmado cuando algunos de los entrevistados expresan no se lleva a cabo un monitoreo como tal, pero en las reuniones de personal se habla de 
cómo van avanzando los proyectos además los comités deben llevar un libro de actas, por medio de reuniones y libros de actas se puede llevar un proceso de planificación continuo y que se relacione con las necesidades que se descubran durante el proceso, pues la información se lleva registrada mediante un libro en el cual se pueden realizar las consultas necesarias y las mejoras prudentes.

Las acciones y análisis del plan llevan a una toma de decisiones que sean de mejoramiento para los miembros de la comunidad a la cual pertenece el centro educativo, en el caso del Liceo Nocturno de Ciudad Colón uno de los participantes expresa: dentro de las acciones del plan están ayudar a quienes padecen de drogadicción, alcoholismo, madres solteras, deserción escolar de centros diurnos. Finalmente, con respecto de la planificación institucional cabe destacar que todas las instituciones educativas tienen conciencia que las necesidades comunales se deben incorporar a la plan anual operativo de cada institución. Sin embargo, en la puesta en práctica de las acciones concretas y la participación de la comunidad en estas no es lo suficientemente efectiva.

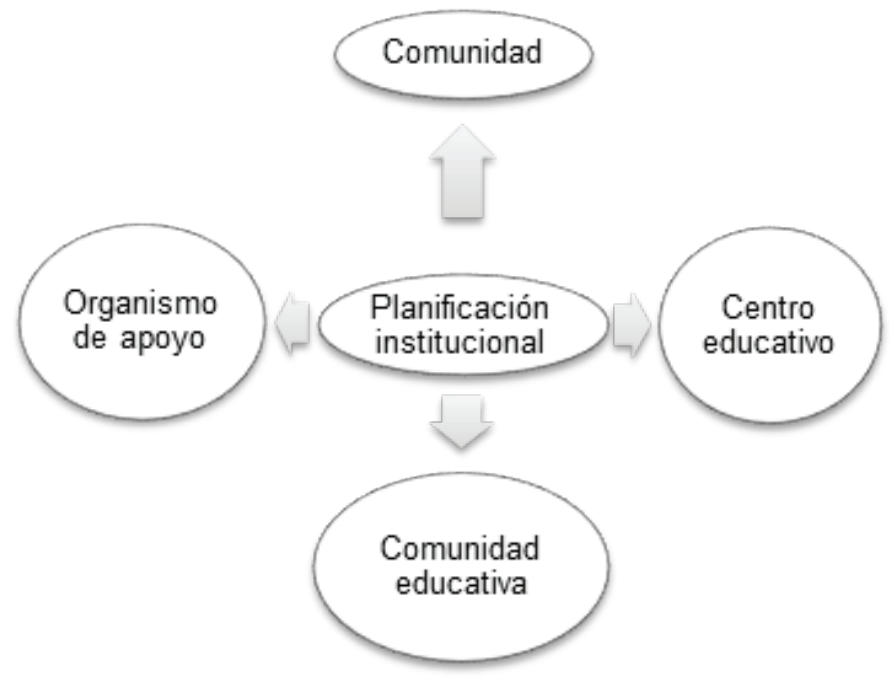

Para realizar un efectivo proceso de planificación de acciones todas las organizaciones 
educativas deben tomar en cuenta a sus participantes y basan sus planes de acción en estos tal y como lo ejemplifica la Figura 1:

Figura 1. Planificación institucional de los centros educativos desde la óptica del gestor educativo

Fuente: Elaboración propia a partir de las entrevistas realizadas a sujetos participantes, 2012.

\section{Proceso de organización en las instituciones educativas para vincular la comunidad.}

La organización es un proceso necesario y muy importante tanto para la institución, para los responsables de la misma como para la vinculación entre ésta y la comunidad. Es preciso poseer además de orden y secuencia en las actividades propuestas, rangos de autoridad y un excelente sistema de comunicación, en este caso entre la comunidad y la institución.

Para ello y con el propósito de analizar las estrategias de organización institucional de los centros educativos que forman parte del estudio y su vinculación con la comunidad se trabajó con los siguientes indicadores según las categorías de análisis derivadas de los objetivos de la investigación: proceso administrativo, normado y estructurado, ejecuta un diagnóstico, ordena y da secuencia a las acciones, agrupa actividades, funciones y tareas para ejecutar un plan, asigna personal para realizar las actividades, asigna a cada miembro del personal sus responsabilidades, determina rangos de autoridad, revisa y controla el proceso, posee un sistema de comunicaciones, inscrita en la normativa legal e inmersa en una realidad

Una vez analizada la información proporcionada por los sujetos participantes del estudio, supervisores, directores y docentes de las cinco instituciones coinciden en que en todas ellas se lleva a cabo el proceso de organización; este proceso se cumple según las directrices generales que se reciben a través de la supervisión y ésta a su vez de directrices del MEP. Concuerdan las respuestas en que una forma común de organización presente en las instituciones, la constituyen los comités, estos incorporan a la totalidad del personal.

En la integración del personal en los diferentes comités, los administradores de las instituciones pertenecientes al estudio, indican que ellos se ven en la necesidad de identificar las capacidades del personal, entendiendo esta selección como la identificación del talento humano, consideran que los comités se integran tomando en cuenta los intereses y capacidades del personal. Tienen presente los directores que en todas las instituciones se siguen criterios normados y estructurados, con reuniones periódicas, acuerdos que se registran en libros de actas, rendición de informes, en forma mensual, trimestral y anual, de acuerdo con las políticas vigentes del MEP, atendiendo a la Ley de Control Interno. Los cinco directores entrevistados, manifiestan que para ejecutar el plan anual el director debe conocer la comunidad en la que se encuentra inmersa la institución para identificar las debilidades y fortalezas de la misma y los 
procesos de vinculación existente entre comunidad - institución, así como del personal que dirige, coordina y ubica en los diferentes comités o comisiones

Al respecto, cuatro de los cinco supervisores concuerdan en que los directores asignan responsabilidades a aquellos funcionarios que poseen dentro de sus características personales un compromiso con la institución y que además poseen disponibilidad para asumir ciertos retos y responsabilidades en pro de la institución. Coincide con los supervisores la respuesta suministrada por la coordinadora del primer ciclo de la Escuela Santiago Crespo yel representante del organismo de apoyo de la Unidad Pedagógica Rafael Hernández Madriz, cuando responden que se toman decisiones y se integran comités que favorecen el buen funcionamiento de las instituciones, todos estos comités al realizar los planes contextualizan e incorporan en la medida de lo posible a algunos padres o miembros de la comunidad estudiantil.

Como parte de la labor administrativa el administrador de la educación agrupa a su personal en comités que poseen responsabilidades previamente asignadas, éstas deben ser ejecutadas respondiendo al plan de trabajo, por medio de los comités tanto docentes, como padres de familia y grupos de apoyo ejecutan las acciones necesarias para concretar dicha labor, los rangos de autoridad se logran mediante acciones concretas como son: toma de decisiones, comunicación de las mismas y puesta de marcha de esas decisiones.

Los procesos de revisión y control son realizados por la totalidad de las instituciones encuestadas, según los criterios como los siguientes: cumplimiento de cronogramas, realización de reuniones, entrega de informes tanto a los organismos de apoyo, dirección supervisión, regional. Las principales formas en que se lleva a cabo el proceso de revisión y control ejercido en las instituciones educativas son los cronogramas, las reuniones periódicas y los informes. Al analizar las respuestas ofrecidas por las personas entrevistadas se determina que el total de las instituciones que forman parte de este estudio coinciden en que el sistema de comunicación utilizado por todas ellas son las circulares y reunión. En general los diferentes sujetos de la investigación, manifiestan de forma directa la poca participación de las comunidades en el desarrollo de las actividades de la institución.

\section{Estrategias de dirección implementadas en las organizaciones educativas para vincu-}

\section{lar el centro educativo y la comunidad.}

La dirección institucional es un área muy importante en la gestión de una organización educativa, porque permite alcanzar el máximo rendimiento de los trabajadores, implanta el entusiasmo por el trabajo, de acuerdo con las metas institucionales y los requerimientos sociales. Por tanto, la dirección implica mandar, influir y motivar a los empleados para que realicen tareas esenciales, conjuntamente, las relaciones y el tiempo son fundamentales para las actividades de dirección. De este modo, los gerentes, al establecer el ambiente adecuado, ayudan a sus 
empleados a hacer su mejor esfuerzo (Stoner, Freeman y Gilbert, 1996).

Para analizar las estrategias de dirección institucional de los centros educativos del estudio y su vinculación con el centro educativo y la comunidad se tomaron en cuenta los siguientes indicadores: relación del entorno con la organización educativa, motivación provocada por las necesidades institucionales y sociales, comunicación asertiva entre el administrador de la educación y los organismos de apoyo educativo comunales, entusiasmo que se evidencia en el administrador educativo y en los miembros de apoyo de la comunidad, resolución de conflictos adecuada entre los organismos de apoyo y la gestión de las instituciones en la implementación y coordinación de proyectos comunales, funciones administrativas que toman en cuenta el vínculo centro educativo y la comunidad, liderazgo del director para influir en la toma de decisiones de los distintos grupos sociales que colaboran con la institución, trabajo en equipo que vincula la comunidad con la organización educativa y atención a las

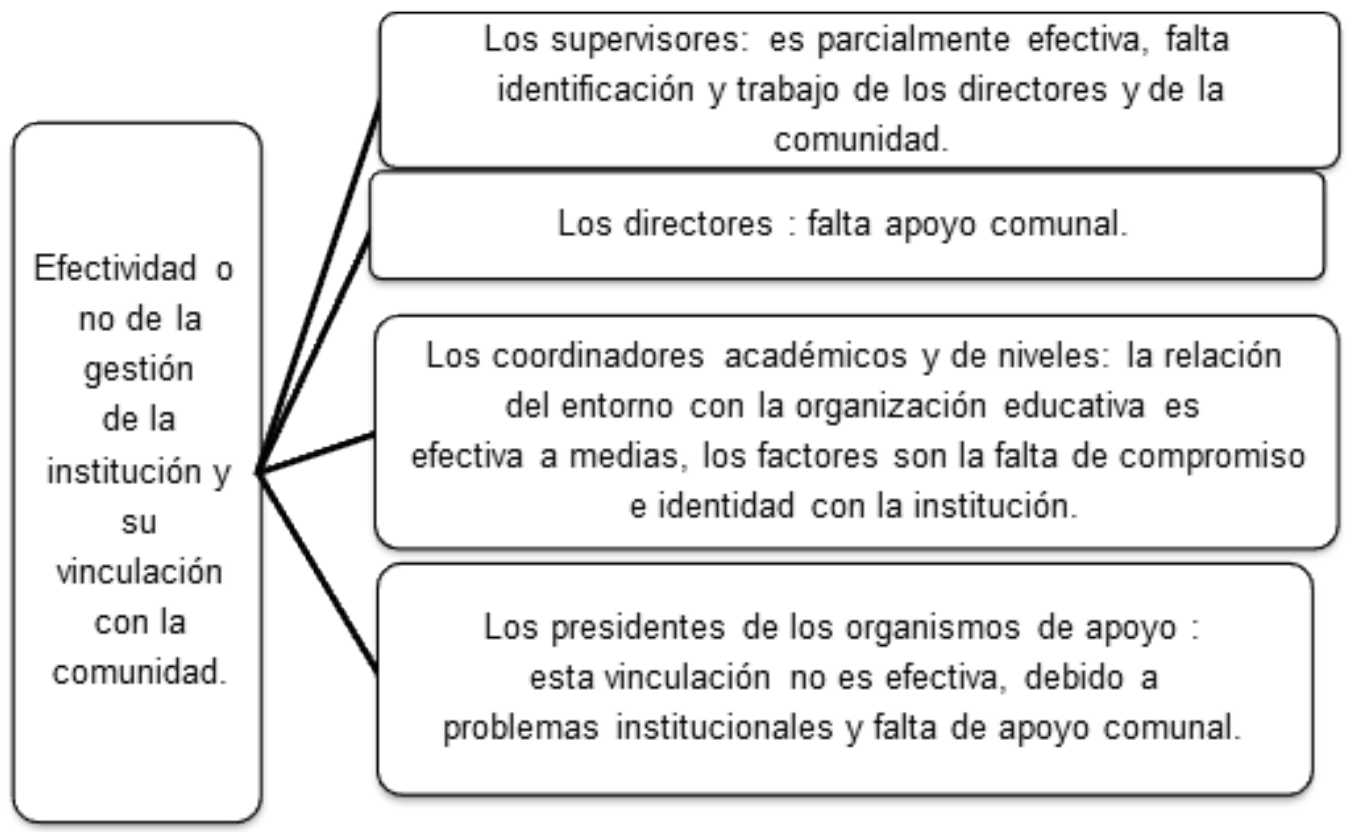

necesidades comunales.

La siguiente figura muestra las respuestas dadas por los entrevistados con respecto del tema de la gestión de la institución y su vinculación con la comunidad:

Figura 2. La gestión de la institución educativa y su vinculación con la comunidad 
Nota: Elaboración propia a partir de la Entrevista aplicada a supervisores de circuito, administradores de la educación, coordinadores académicos o de nivel y representantes de los organismos de apoyo de las distintas instituciones educativas, 2012.

Al respecto, Lejtman (1996) citado por García, Rojas y Campos (2002) explica que "la escuela como institución integral requiere una visión comprensiva un abordaje totalizador, una relación dialéctica entre procesos y resultados, de la que es responsable quien o quienes ejerzan la conducción general" (p. 2). Por lo tanto, la dirección debe procurar que esta relación entre la organización educativa y comunidad sea la más adecuada para llevar a cabo su tarea principal, que es la de formar mejores ciudadanos que sean capaces de integrarse de manera correcta y precisa a la sociedad y a sus respectivas comunidades de convivencia.

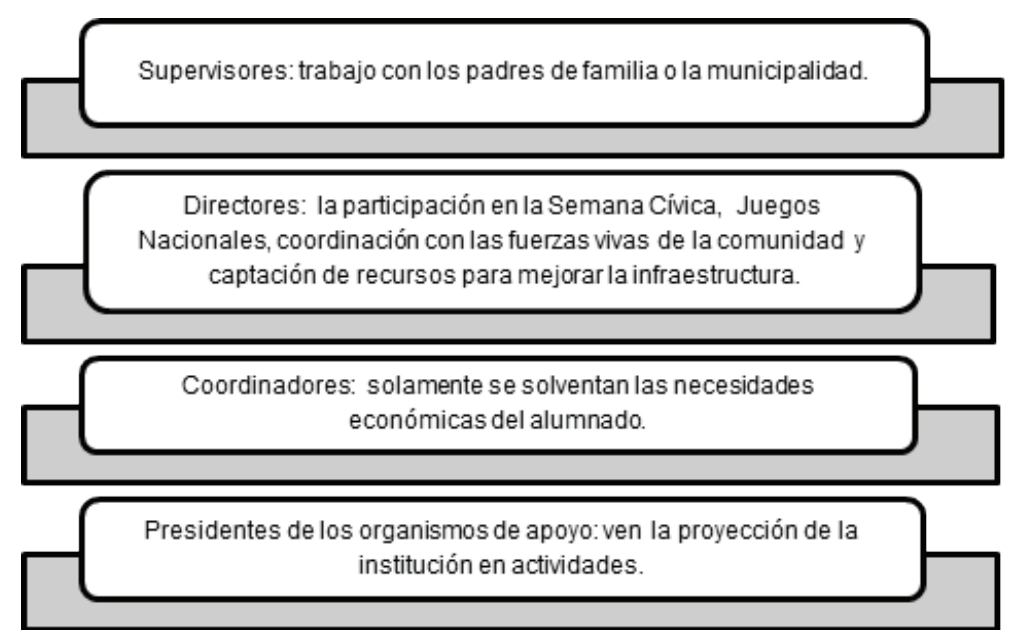

Esta predisposición de las personas para realizar ciertas acciones incentiva la implementación de los proyectos con la comunidad y el centro educativo. Las respuestas dadas por los informantes son representadas en la siguiente figura:

Figura 3. Formas en que la motivación es provocada por las necesidades institucionales y sociales en las organizaciones participantes del estudio

Fuente: Elaboración propia a partir de la Entrevista aplicada a supervisores de circuito, administradores de la educación, coordinadores académicos o de nivel y representantes de los organismos de apoyo de las distintas instituciones educativas, 2012.

En cuanto a la comunicación asertiva entre el administrador de la educación y los organismos de apoyo educativo comunales, los supervisores opinan que la comunicación que vincula a la gestión administrativa con el contexto comunal, debe ser una comunicación asertiva y horizontal, capaz de transmitir información, sentimientos, vivencias, de recibir ideas y mensajes entre los individuos. En lo referente al entusiasmo que se evidencia en el administrador 
educativo y los miembros de apoyo de la comunidad, se busca que exista atención y esfuerzo dedicados con perseverancia e interés al progreso de una actividad o trabajo. Belker y Topchik (2005) compilan la información básica sobre el concepto y características del entusiasmo, mismas que se pueden aplicar al trabajo del administrador educativo y los miembros de los organismos de apoyo de la comunidad, estas son: motivación, atención, esfuerzo, perseverancia, interés, progreso, identificación, fin positivo y adhesión.

En cuanto al entusiasmo presente en el trabajo de los administradores de la educación y los organismos de apoyo de la comunidad, todos los directores de las instituciones afirman que el entusiasmo es una característica que se evidencia en el trabajo. Para todos los presidentes de los organismos de apoyo, sí hay entusiasmo. Las formas en que el entusiasmo se evidencia en el trabajo de los administradores de la educación y los organismos de apoyo de la comunidad son: el trabajo en equipo, el interés por la comunidad, el interés por la institución, los hijos, los familiares son una razón para trabajar. Las manera en que la falta de entusiasmo se evidencia son: los obstáculos para que los proyectos se lleven a término, la falta de identificación con la comunidad y con la institución, la salida para buscar ayuda, las tareas que son impuestas, la falta de disponibilidad y la falta de participación de los padres de familia

Con respecto de la resolución de conflictos adecuada entre los organismos de apoyo y la gestión de las instituciones en la implementación y coordinación de proyectos comunales los supervisores aclaran distintas situaciones; el supervisor del Colegio San José de la Montaña comenta que no se han presentado conflictos en la gestión actual. Las respuestas a la resolución de conflictos adecuada entre los organismos de apoyo y la gestión de las instituciones en la implementación y coordinación de proyectos comunales se resumen en el seguimiento de los procedimientos, en cada institución existe una comisión de resolución de conflictos, se acude a la supervisión para una conciliación o se da una visita a la institución, el diálogo es fundamental y la votación se realiza cuando algún proyecto no se puede llevar a cabo o no es del agrado de todos.

En cuanto a las funciones administrativas que toman en cuenta el vínculo centro educativo y comunidad, se indagó sobre la incidencia positiva o negativa de la implementación de los proyectos con la comunidad y el centro educativo, las respuestas sobre la incidencia positiva se basan en el colaboración de la comunidad, las buenas ideas, la atención a las necesidades institucionales y las reuniones; en cuanto a la incidencia negativa, se destaca el surgimiento de conflictos, la falta de tiempo para las reuniones, la falta de comunicación, la toma de decisiones de forma unilateral, los pocos espacios para diagnosticar, planear, coordinar y ejecutar proyectos.

Las formas de liderazgo de los administradores de la educación en la toma de decisiones de los distintos grupos sociales que colaboran con las instituciones se evidencia en el trabajo exitoso con los organismos sociales de la comunidad, su capacidad y experiencia, la no 
imposición y arbitrariedad, el diálogo y que toma en cuenta las opiniones de los demás.

Al respecto, es necesario que la administración de la educación propicie un liderazgo donde se planee, informe, evalúe, arbitre, controle, recompense, estimule, penalice, ayude en el alcance de los objetivos y satisfaga necesidades (Chiavenato, 2004).

A los supervisores se les preguntó sobre su propio liderazgo y la influencia en la toma de decisiones de los organismos de apoyo que colaboran con la institución, a lo que contestaron que las maneras en que estas acciones se realizan son con capacitaciones a docentes, directores y grupos de apoyo, ayuda incondicional y documentos que informen sobre las necesidades de la institución, respeto a las sugerencias y opiniones, reuniones, trabajo con los docentes y finalización de proyectos.

En relación con la atención de las necesidades comunales desde las acciones concretas es necesario destacar el cumplimiento de las metas y los objetivos de las organizaciones, pero es necesario tomar en cuenta las características de generación de resultados, herramientas y satisfacción de necesidades institucionales (Chiavenato, 2009).

Para los supervisores de circuito, las formas en que se realiza la atención de las necesidades comunales desde las acciones concretas de la institución educativa son: la importancia a la calidad de la educación, proyectos contra las drogas, visitas del Ministerio de Salud, charlas con Instituto sobre Alcoholismo y Farmacodependencia (IAFA), protección de la Guardia de Asistencia Rural, operativos y visitas del Organismo de Investigación Judicial (OIJ), charlas contra la violencia y asistencia del Patronato Nacional de la Infancia (PANI), participación en actos cívicos y comunales, reuniones con los padres de familia, los comités de la comunidad y con los docentes, apertura al diálogo y becas escolares, servicio de comedor y donaciones.

Mecanismos de coordinación empleados entre las organizaciones educativas para la vinculación comunal que se presenten en la cotidianeidad de los centros educativos.

Para analizar los mecanismos de coordinación empleados en las organizaciones educativas participantes del estudio y su vinculación con el centro educativo y la comunidad se tomaron en cuenta los siguientes indicadores: guía de acción para el cumplimiento de los programas, proyectos y planes que articulan el centro educativo con la comunidad, equipos de trabajo desde la perspectiva organizacional del centro educativo, trabajo en equipos y autonomía para la puesta en práctica de los diferentes proyectos, programas, proyectos y planes.

Con respecto de la autonomía, esta se da tanto de parte del centro educativo como por la comunidad, se rescata que esta coordinación entre el centro educativo y la comunidad fortalecen el compromiso entre ambas partes para llevar a cabo las diferentes actividades, cabe 
aclarar que en lo referente a este último tema si los mecanismos de coordinación fortalecen el trabajo de vinculación con la comunidad, la siguiente figura resume las opiniones dadas por los

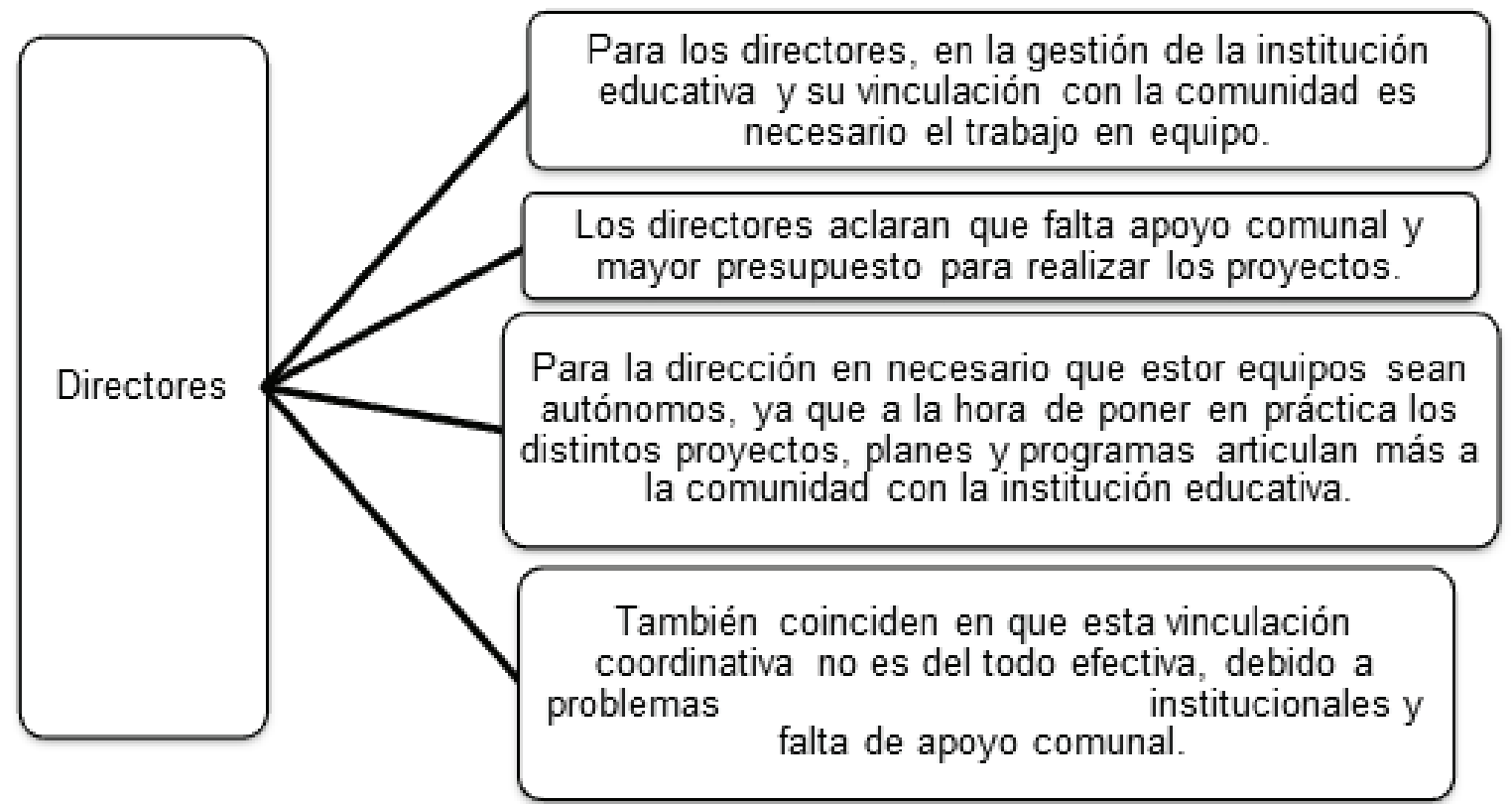

directores:

Figura 4 Coordinación y vinculación con el centro educativo y la comunidad en la implementación de los programas o proyectos según opinión de la dirección

Fuente: Elaboración propia a partir de la Entrevista aplicada a directores, de las distintas instituciones educativas, 2012.

- El organismo de apoyo del Liceo Nocturno de Ciudad Colón lleva un proceso de coordinación de proyectos o planes que articulan con el centro educativo, con una guía en la que se toman todas las decisiones en cuanto a infraestructura y comedor, en las reuniones se le informa a la dirección de los proyectos y de las decisiones tomadas para ellos. Se trabaja en equipo y de manera autónoma, siempre y cuando se mantenga el respeto del presupuesto del centro educativo. Por medio de visitas o llamadas el organismo de apoyo se mantiene cercano a la comunidad.

- $\quad$ Las opiniones de los representantes de los organismos de apoyo con respecto del tema de la coordinación y la vinculación con el centro educativo y la comunidad opinan 
que la implementación de los programas o proyectos: se trabaja en equipo y de manera autónoma, siempre y cuando se mantenga el respeto del presupuesto del centro educativo y las reuniones se anticipan por medio de una agenda para coordinar con antelación los temas que se van a analizar y que son de interés para la institución, se lleva un libro de actas.

- Los coordinadores académicos o de nivel de las distintas instituciones del estudio opinan que la coordinación y la vinculación con el centro educativo y la comunidad en la implementación de los programas o proyectos poseen una organización institucional que ejecuta y elabora los distintos proyectos, programas y planes con ayuda de un cronograma, Existe una autonomía para poner en práctica estos proyectos, tanto del comité de apoyo como de la institución educativa y los mecanismos utilizados en la coordinación apoyan al estudiante y del hecho de que si la junta realiza un proyecto es importante, pero la identificación del docente es parcial.

\section{Criterios de control empleado en las instituciones educativas para la ejecución del proyec-}

\section{to institucional y la articulación con la comunidad.}

Por ser la administración de la educación un proceso sistemático de trabajo organizado, que se encuentra dentro del desarrollo de las instituciones educativas, que toma en cuenta la misión, la visión y los objetivos que se desean alcanzar y que se encuentran regidos por los aspectos educativos, es de interés profundizar en su incidencia con respecto de la vinculación del centro educativo con la comunidad. Para indagar sobre esta temática, se tomaron en cuenta los siguientes indicadores: acciones de control, medidas correctivas que para superar las debilidades, amenazas y desviaciones que enfrenta la institución, mecanismos de control interno y externo, métodos de control de recursos, bienes y operaciones institucionales, método de control externo que se aplica en la institución educativa para la optimización de recursos y articulación de la normativa de control interno y sus reformas

En relación con las acciones de control, que se toman en cuenta en el desarrollo de los proyectos, programas y planes de los centros educativos en vinculación con la comunidad, y por parte de la administración de la educación, y a criterio del Director del Colegio San José de la Montaña, es importante tener en cuenta que los mecanismos de control en los centros educativos son necesarios, sin embargo, hay que ver de qué forma se ponen en práctica y cómo esos mecanismos se verifican en la ejecución de los proyectos, planes y programas en los centros educativos en vinculación con la comunidad y lo que ésta puede hacer para mejorar los procesos educativos y la gestión de los centros educativos para hacer del sistema educativo un óptimo ambiente para los y las estudiantes.

Al indagar con los sujetos participantes del estudio se obtuvo a criterio de la mayoría, que 
las acciones de control son importantes porque asíse rigen los proyectos, planes y programas que se quieren llevar a cabo a través de guías o lineamientos con la participación de la comunidad, no obstante, esas acciones de control no se hacen de forma sistemática (no hay revisión periódica), lo cual indica que no hay un proceso de seguimiento de las acciones que se toman para ejecutar y evaluar los proyectos, planes y programas.

Algunos de los participantes, como la supervisora, el director del centro educativo y el coordinador académico del Liceo Ambientalista de Horquetas reconocen la importancia de mantener en forma constante adecuados procesos de control institucional para vincular el centro educativo con la comunidad, externando criterios como la importancia de esos mecanismos de control interno y externos es nula. Si tuvieran alguna importancia, esos proyectos se realizarían.

En la gestión de los cinco centros educativos que fueron sujetos del estudio en vinculación con la comunidad, los supervisores, directores, coordinadores académicos y miembros de los organizamos de apoyo explican que los mecanismos de control interno y externo son necesarios y muy importantes, ya que a través de esas herramientas, se puede llegar a la óptima toma de decisiones en favor de todos los sujetos involucrados.

Para entender mejor los mecanismos de control interno y externo de los centros educativos, se resume que para los supervisores son muy necesarios, para los directores se puede llegar a la óptima toma de decisiones a favor de todos los sujetos involucrados, para los coordinadores académicos es necesaria la retroalimentación y para los miembros de los organismos de apoyo se debe asegurar la obtención de los objetivos de acuerdo con el plan institucional. En síntesis, los mecanismos de control interno y externo son en realidad componentes primordiales en el desarrollo de los objetivos que se desean alcanzar por medio de los proyectos, planes y programas que los centros educativos tienen.

Las Juntas Administrativa y las Juntas de Educación llevan su control interno, en conjunto con los centros educativos vinculados con las comunidades, se supone que las mismas no están obligadas a dar informes. Los gestores sólo ven el trabajo que ellas realizan, pero no tiene la potestad de alterar la información que se les presenta.

Dentro de las cinco instituciones educativas en estudio, los directores, supervisores y coordinadores académicos expresan que los métodos de control externo son vitales, ya que por medio de ellos se optimizan los recursos que son necesarios para el funcionamiento de todos los centros educativos participantes del estudio. Algunos de los métodos que se llevan a cabo son informes e inventarios, también control interno, conocimiento de algunas leyes en el caso de las Juntas de Educación y Juntas Administrativas.

Para finalizar esta categoría acerca de control externo, se puede también mencionar que se llevan a cabo auditorías, por medio de las cuales se redacten informes que sirvan de base y 
pruebas para todo lo que se hace. El control interno de la institución educativa en vinculación con la comunidad debe ser adecuado a la realidad institucional y las necesidades que esta presenta. Para reiterar, uno de los participantes dijo "el control interno se debe de adecuar en conformación con el centro educativo y la comunidad a la cual esta pertenece y a las necesidades que se presentan en ambas".

Para ejemplificar lo anterior, la figura 5 explica los criterios de control empleados en las

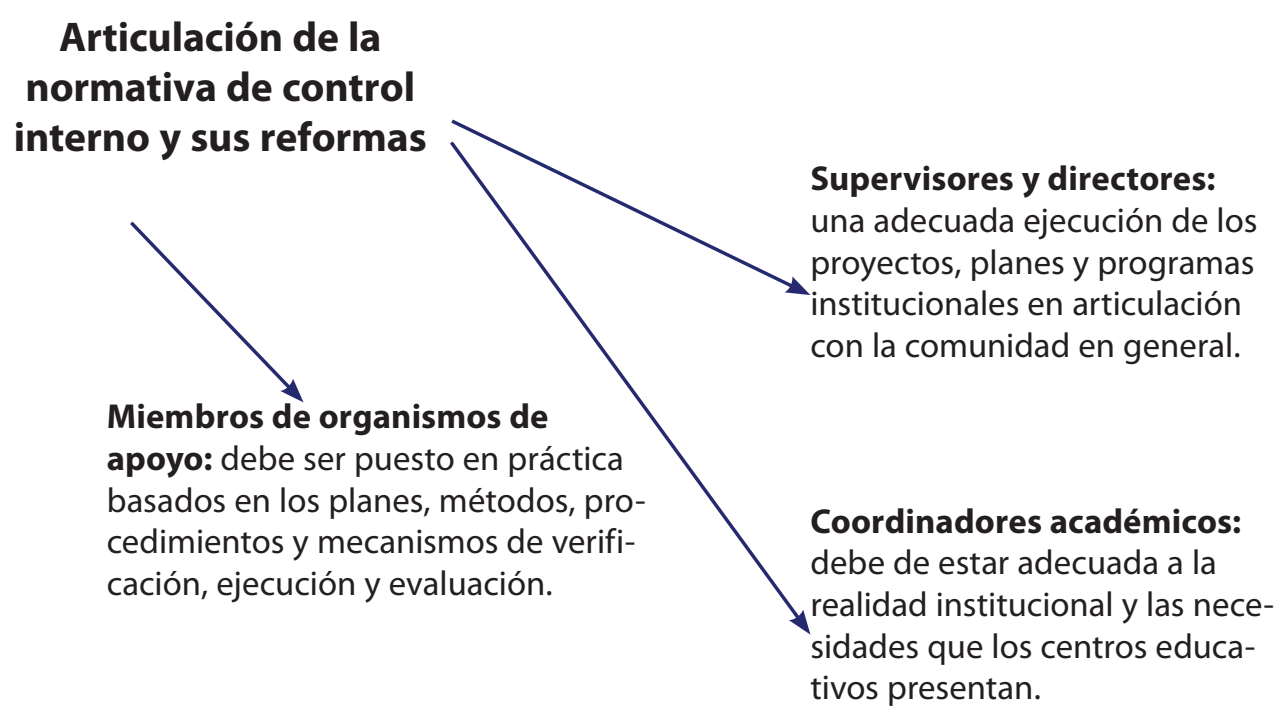

instituciones educativas participantes:

Figura 5. Criterios de control empleado en las instituciones educativas para la ejecución del proyecto institucional y la articulación con la comunidad

Fuente: Elaboración propia a partir de los datos proporcionados por los informantes de los centros educativos Unidad Pedagógica Rafael Hernández Madriz, Escuela Santiago Crespo Calvo, Liceo Ambientalista de Horquetas, Colegio San José de la Montaña y Liceo Diurno de Ciudad Colón, 2012.

En cuanto al control interno, los directores, supervisores y coordinadores académicos de los cinco centros educativos se refieren a que el establecimiento y desarrollo de ese control en instituciones educativas públicas costarricenses, con respecto de la vinculación del centro educativo con la comunidad, es responsabilidad de los diferentes representantes legales correspondientes como los supervisores, directores, personal docente y administrativo 
comités de apoyo y comunidad. Sin embargo, la ejecución y la aplicación de los métodos y procedimientos al igual que la calidad, eficiencia y eficacia del control interno, también será de responsabilidad de los gestores de cada una de las distintas dependencias de las entidades y organismos educativos con su vinculación con las comunidades en donde se encuentran los centros educativos.

\section{Métodos de evaluación empleados en las organizaciones educativas con respecto de la ejecución del plan institucional y la vinculación con la comunidad.}

Es relevante que la administración de la educación considere los métodos de evaluación empleados en las organizaciones educativas con respecto de la ejecución del plan institucional y la vinculación con la comunidad, esto por cuanto, la evaluación es, según Stufflebeam (1971) en Bolaños y Navas (2004), un proceso para definir, obtener y proporcionar información necesaria para juzgar alternativas en una decisión. Aunado a lo anterior, es evidente que la evaluación es un conjunto de acciones lideradas por los directores de los centros educativos para supervisar y analizar el logro de resultados de los distintos proyectos, programas o planes que se llevan a cabo en conjunto con la comunidad a la cual pertenece.

Para describir los métodos de evaluación empleados en las organizaciones educativas, la ejecución del plan institucional y la vinculación con la comunidad se tomaron en cuenta los siguientes indicadores: supervisión del desarrollo de los diferentes programas, proyectos y planes, análisis de los resultados de los distintos proyectos, programas o planes, monitoreo en conjunto con la comunidad de los planes, programas y proyectos y comparación de los resultados con los objetivos planteados y la utilización de los mismos para la mejora de los diferentes procesos. 
Con respecto de la supervisión del desarrollo de los diferentes programas, proyectos y planes, las principales características de supervisión del desarrollo de los diferentes programas,

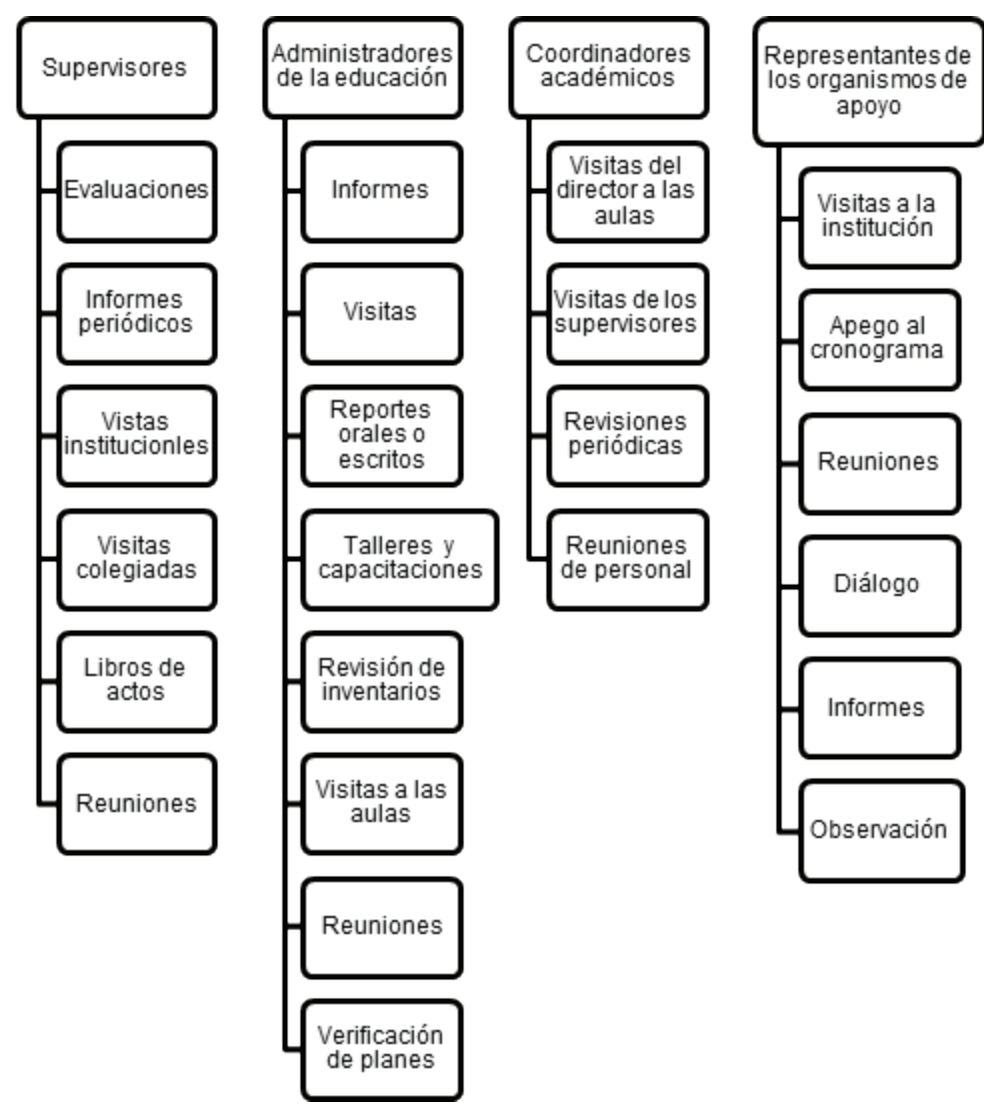

proyectos y planes se destacan la comprensión y la valoración, la evaluación formativa, la sumativa y la sociopolítica y la verificación de cuánto de la planificación fue logrado y qué metas fueron alcanzadas. La siguiente figura muestra la información:

Figura 6. Formas de supervisión del desarrollo de los diferentes programas, proyectos y planes

Fuente: Elaboración propia a partir de la Entrevista aplicada a supervisores de circuito, administradores de la educación, coordinadores académicos o de nivel y representantes de los organismos de apoyo de las distintas instituciones educativas, 2012. 
En relación con el análisis de los resultados de los distintos proyectos, programas o planes, los supervisores aclaran distintas maneras de analizar; por ejemplo, en el Liceo Nocturno de Ciudad Colón se realizan informes periódicos. En el Colegio San José de la Montaña, a partir de una sistematización de la información, se recurre al análisis estadístico. En el Liceo Ambientalista de Horquetas se realizan reuniones con los comités de calidad de la educación. En la Escuela Santiago Crespo Calvo la supervisión debe entregar en forma periódica los avances de planes de trabajo a la regional por lo que antes se revisan en forma porcentual. En la Unidad Pedagógica Rafael Hernández cuando el proyecto termina se realiza una reunión para analizar y pros y contras del proyecto.

Los administradores de la educación expresan que uno de los elementos más utilizados es la reunión. En el Liceo Nocturno de Ciudad Colón se realizan reuniones. En el Colegio San José de la Montaña se hace un análisis oral de los resultados que se han obtenido de esos programas, planes y proyectos. En el Liceo Ambientalista de Horquetas se realizan la evaluación de los mismos. En la Escuela Santiago Crespo Calvo por medio del análisis de resultados. En la Unidad Pedagógica Rafael Hernández en las mismas reuniones se analizan los resultados y los encargados de las actividades realizan los cambios que consideren pertinentes para futuras acciones.

Los coordinadores de nivel o académicos también comentan que sí se realizan análisis de los resultados. En el Liceo Nocturno de Ciudad Colón con informes. En el Colegio San José de la Montaña quizás a través de una reunión, pero falta una base más científica para el análisis, se puede decir que es un FODA, pero hay una observación muy superficial. Se hace una recopilación, pero no es algo muy profundo. En el Liceo Ambientalista de Horquetas se realizan evaluaciones constantes y cualitativas. En la Escuela Santiago Crespo Calvo se desarrollan las revisiones. En la Unidad Pedagógica Rafael Hernández la coordinadora de I ciclo contesta que en las reuniones y se trata de ver qué funcionó y qué no para solucionarlo o mejorarlo en próximas actividades, pero la coordinadora de II ciclo dice que no se analizan.

Los representantes de los organismos de apoyo comentan distintas acciones que se realizan para analizar los resultados de los distintos proyectos o planes. En el Liceo Nocturno de Ciudad Colón en las reuniones se discuten sugerencias y que los proyectos queden concluidos. En el Colegio San José de la Montaña y el Liceo Ambientalista de Horquetas por medio de informes y se discuten en alguna reunión. En la Escuela Santiago Crespo Calvo con reuniones y en forma de porcentajes los avances. Y en la Unidad Pedagógica Rafael Hernández no se analizan los resultados. Se cumple parcialmente lo que Cardona citado por Gento (2008) explica al decir que, potenciar la calidad de la enseñanza es un objetivo deseable y se debe admitir que la evaluación de los sistemas educativos es un factor que favorece la calidad y la mejora de la enseñanza. 
Los supervisores de los centros educativos consideran que esta evaluación sí se realiza, aunque de distintas maneras. La supervisora del Liceo Nocturno de Ciudad Colón manifestó que con la comunidad y los organismos de apoyo no, pero se le pregunta más que todo al director cómo van los proyectos y si requiere de alguna ayuda extra. En el Colegio San José de la Montaña mediante la entrevista personal, visitas y recopilación de la información. En el Liceo Ambientalista de Horquetas mediante encuestas y reuniones. En la Escuela Santiago Crespo Calvo con informes y en forma porcentual esos informes por trimestre y en forma anual y en la Unidad Pedagógica Rafael Hernández por medio de diferentes reuniones.

Los administradores de la educación afirman que sí se realizan monitoreos, pero de distintas maneras, con reuniones, diagnósticos, llamadas telefónicas y visitas a las aulas y proyectos. Los coordinadores académicos y de nivel poseen distintas opiniones en el tema del monitoreo, en conjunto con la comunidad, de los planes, programas y proyectos durante y al final del proceso educativo. Aunado a lo anterior, es importante recalcar lo que Cardona en Gento (2008) aclara, debe existir conciencia en los miembros de la comunidad escolar acerca de lo positivo de la reflexión colaborativa y del trabajo en equipo, por lo que es imprescindible una cultura auto-evaluadora que favorezca el análisis de los discursos y proyectos.

Los presidentes de los organismos de apoyo también manifiestan que la carencia de monitoreos en conjunto con la comunidad, de los planes, programas y proyectos durante y al final del proceso educativo. En lo que concierne al monitoreo, en conjunto con la comunidad, de los planes, programas y proyectos durante y al final del proceso educativo.

En cuanto a la comparación de los resultados relacionados con los objetivos planteados y la utilización de los mismos para la mejora de los diferentes procesos es importante destacar las opiniones de los supervisores de las distintas instituciones. En el Liceo Nocturno de Ciudad Colón se trabaja en resultados según la promoción anual de estudiantes, pero no en relación con el plan anual. En el Colegio San José de la Montaña la comparación es establecer la relación entre el producto esperado y el resultado obtenido y a partir de todo se toman las decisiones correspondientes. En el Liceo Ambientalista de Horquetas mediante cuadros comparativos, para implementar las mejoras a los procesos. En la Escuela Santiago Calvo Crespo la Unidad Pedagógica Rafael Hernández cada institución debe aplicar el resultado de su avance para mejorar e implementar estrategias para poder llevar a cabo en forma completa su plan de trabajo. En este sentido los supervisores ayudan a los centros escolares para que sean más eficaces y para que desarrollen sus planes, programas y objetivos ya que la tendencia actual no es imponer reglas específicas y regulaciones estrictas que deberían ser seguidas en todas las ocasiones.

Para los coordinadores académicos la comparación de los resultados relacionados con los objetivos planteados y la utilización de los mismos para la mejora de los diferentes 
procesos se realizan pero de manera escueta.

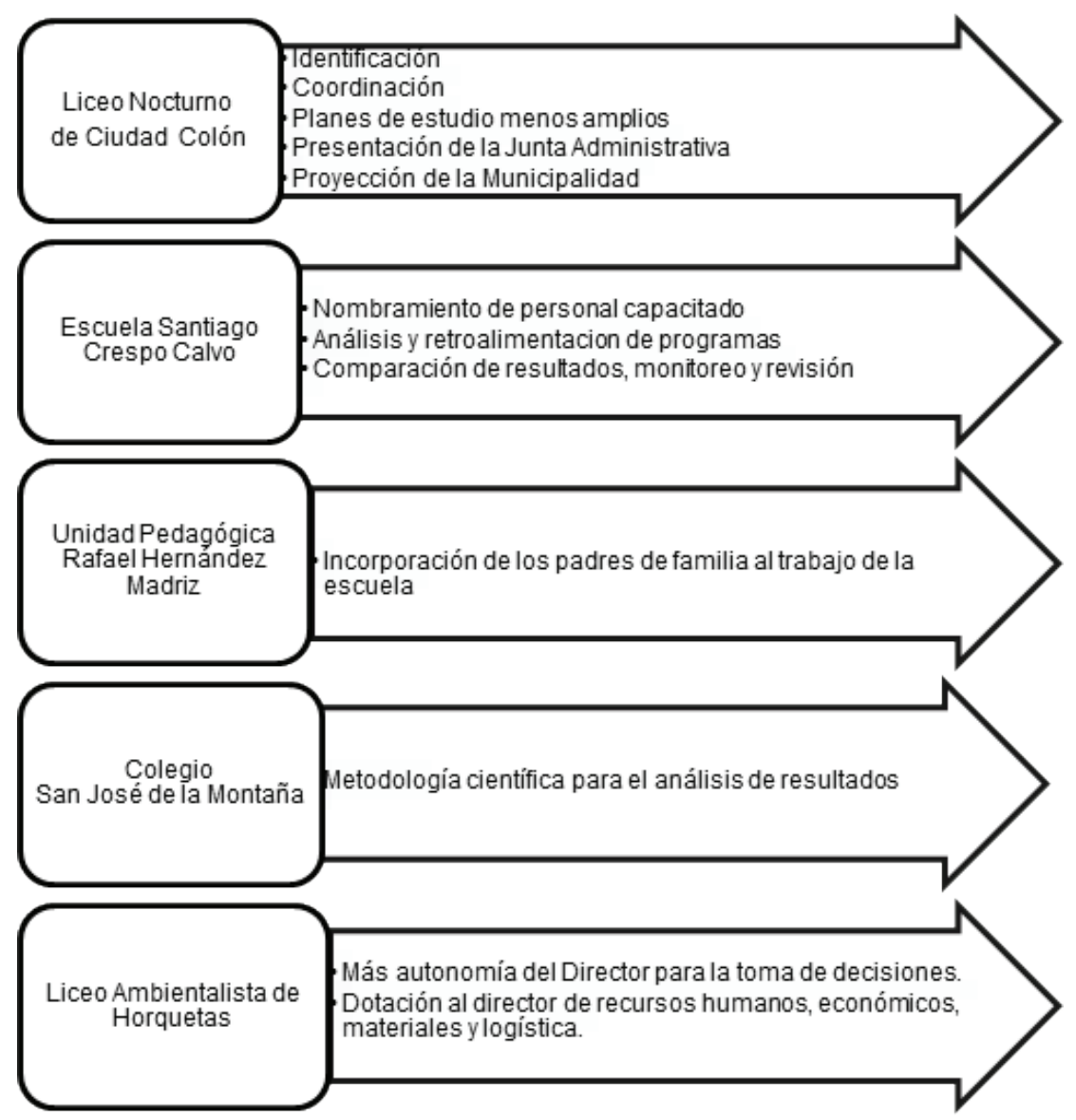

Para los representantes de los organismos de apoyo al final de los proyectos se realiza algún tipo de comparación de resultados. Las sugerencias al respecto se indican seguidamente:

Figura 7. Recomendaciones de los coordinadores académicos y de nivel 
Fuente: Elaboración propia a partir de la Entrevista aplicada a coordinadores académicos y de nivel, 2012

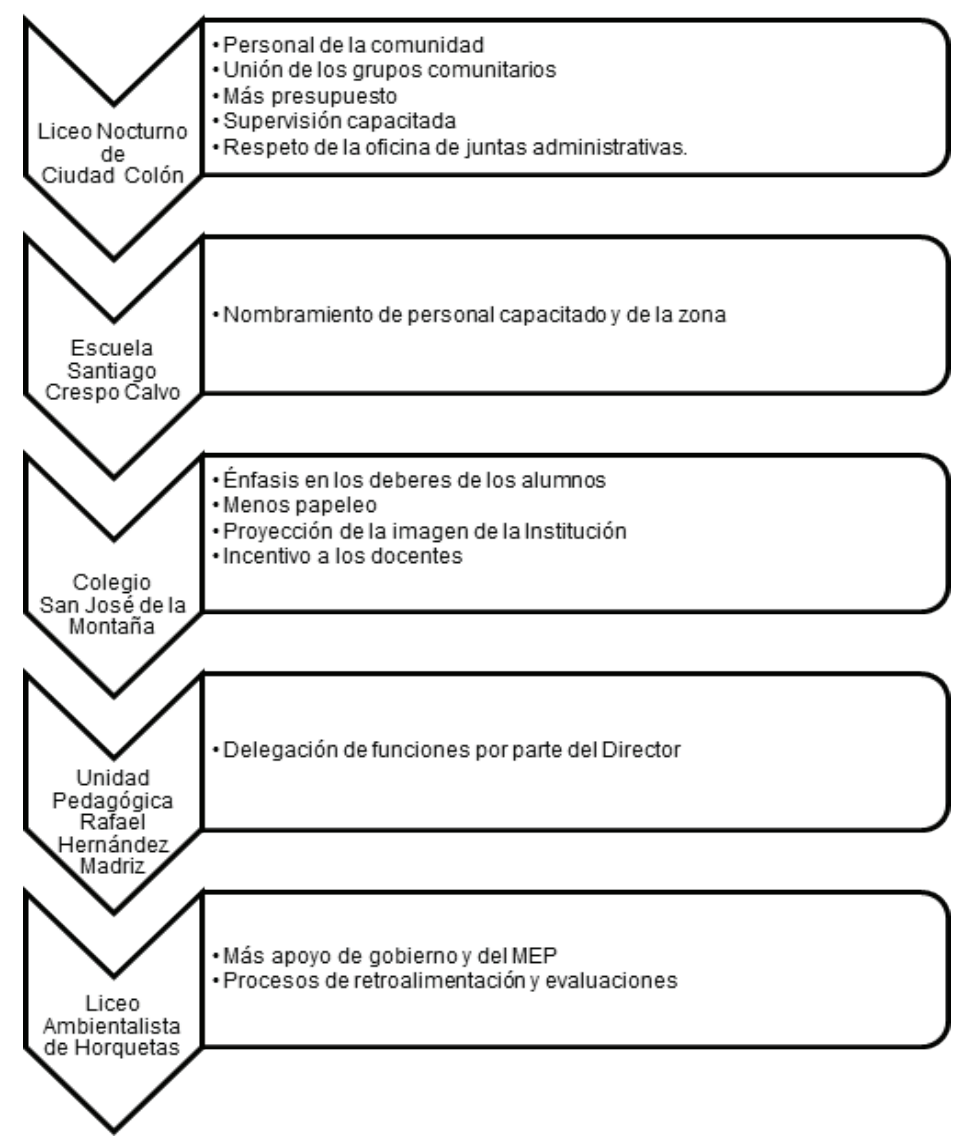

Las recomendaciones de representantes de los organismos de apoyo para que la labor de supervisión sea desempeñada con mayor efectividad y eficiencia en relación con la vinculación de la gestión de la educación y la comunidad se resumen en la siguiente figura:

Figura 8. Recomendaciones de los representantes de los organismos de apoyo a la supervisió

Fuente: Elaboración propia a partir de la Entrevista aplicada a coordinadores académicos y de nivel, 2012.

Como puede notarse, una de las quejas más recurrentes de los diferentes entrevistados es el excesivo cumplimiento de trámites y "papeleos", muchas veces son innecesarios, tediosos 
y que eliminan el tiempo para actividades que puedan involucrar el centro educativo con la comunidad.

En cuanto al cumplimiento de las expectativas de la labor directiva, los diferentes sujetos entrevistados opinan:

- Supervisores de circuito: La Supervisora del Liceo Nocturno de Ciudad Colón no percibe un trabajo al 100\%, este año ha mejorado mucho la relación con la Junta Administrativa, porque se toma en cuenta al Director y lo que este dice. El supervisor de la Escuela Santiago Crespo Calvo explica que por las capacidades del personal que labora en el circuito escolar las expectativas que como supervisor se han logrado en alto grado. En la Unidad Pedagógica Rafael Hernández Madriz a un 80 \%. En el Colegio San José de la Montaña en forma mediana (debido al tiempo que ha estado el centro educativo bajo su responsabilidad). Y en el Liceo Ambientalista de Horquetas en realidad no del todo, la labor de dirección es muy compleja y delicada.

- Administradores de la educación: El administrador de la educación del Liceo Nocturno de Ciudad Colón explica que cuando él llegó a la dirección, el Colegio tenía un proceso judicial con la directora del momento, y solo 80 ó 90 estudiantes matriculados, el trabajo en equipo ha sido fundamental, hoy hay entre 300 y 400 estudiantes. Sabe que el nombramiento de la Junta Administrativa no es respetado en la terna que se envía a la Municipalidad. Hay avances, pero la proyección es difícil. El tiempo es un adversario y los alumnos trabajan en su gran mayoría, los que tienen capacidades como la música o el arte o inclinaciones científicas no pueden participar en concursos estudiantiles porque son en el día y ellos no pueden faltar a sus trabajos.

Según la directora de la Escuela Santiago Crespo Calvo, la labor directiva no se lleva a cabalidad en un máximo y de manera efectiva, ya que la excesiva elaboración de documentos resta tiempo. La directora de la Unidad Pedagógica Rafael Hernández Madriz está satisfecha con su labor y evidencia que la comunidad la ha acogido, dice ser líder e involucrar al personal en la realización de actividades.

El director del Colegio San José de la Montaña explica que se ha cumplido un $50 \%$ de los proyectos que se han propuesto. Sin embargo, hay que trabajar más para ver cómo la dirección optimiza los recursos y todo lo que beneficie a la comunidad y al centro educativo.

El director del Liceo Ambientalista de Horquetas considera que sí se han cumplido sus expectativas, sin embargo debido a las diferentes poblaciones que pasan por nuestra institución las mismas cambian debido a los retos que se presentan.

- Coordinadores académicos: El coordinador del Liceo Nocturno de Ciudad Colón expresa que en un $60 \%$, porque a la gestión de la institución le falta más identificación 
con la institución, en el caso de la coordinación en un 70\%, porque la función del coordinador está muy limitada a las asignaciones del Director, hay mucha papelería.

El coordinador de la Escuela Santiago Crespo Calvo explica que es un proceso, los directores dedican mucho tiempo a llenar de documentos superfluos, tediosos y a reuniones innecesarias y en muchas ocasiones no pueden cumplir con los proyectos que se han planteado.

En la Unidad Pedagógica Rafael Hernández Madriz la coordinadora de I ciclo aclara que la Directora trabaja bien, no presiona al personal, cada quien trabaja a su ritmo. Sin embargo, son los padres de familia los que no colaboran mucho y esto ocasiona que se duplique el trabajo en la realización de actividades o bien haya desmotivación para este tipo de acciones. La coordinadora de II ciclo explica que la gestión de la institución solo ha buscado tener autoridad, falta fomentar el trabajo en equipo

La coordinadora del Colegio San José de la Montaña especifica que se han cumplido muchos objetivos sin estar visualizados desde la dirección. Se han alcanzado muchos resultados sin seguir ningún programa específico, pero se podrían planificar los objetivos de mejor manera para obtener resultados eficaces y eficientes. Y el coordinador del Liceo Ambientalista de Horquetas especifica que es necesario ver los resultados a mediano o largo plazo.

- Representantes de los organismos de apoyo: La labor directiva en el Liceo Nocturno de Ciudad Colón, según los entrevistados son: Mejor relación con la Junta Administrativa, avances, el tiempo es un adversario, el irrespeto en el nombramiento de la Junta Administrativa, la falta de identificación, el trabajo coordinado con la Municipalidad, la falta de ayuda a los docentes, la poca participación comunitaria de los alumnos, el comedor nocturno, la finalización de proyectos.

La labor directiva en la Escuela Santiago Crespo Calvo se resume en capacidad docente, excesiva elaboración de documentos, procesos realizados y poco presupuesto. Las expectativas de la labor directiva en la Unidad Pedagógica Rafael Hernández Madriz se compendian en la labor directiva, la falta de trabajo, la satisfacción, la aceptación de la comunidad, el liderazgo directivo, el respeto al personal, la poca participación de los padres de familia, la falta de fomento del trabajo en equipo u la accesibilidad y disposición de diálogo.

Las expectativas de la labor directiva en el Colegio San José de la Montaña, según los informantes se resumen en falta de trabajo, falta optimización de recursos, carencia de procesos científicos en la planificación, diálogo, falta de identificación con el centro educativo y con la comunidad.

Aunque la mayoría de los supervisores contestó estar satisfecho con su labor en el circuito escolar correspondiente, es necesario que los mismos tomen en cuenta que las 
organizaciones escolares son parte de un sistema social más amplio y sus estructuras internas se ven afectadas por el contexto. Los centros educativos no existen como realidades individuales y al margen de los sistemas sociales, culturales, profesionales, políticos, artísticos o económicos (González, 2003).

\section{Conclusiones}

En lo que respecta a la planificación y por medio de la información analizada se concluye que el proceso de planificación no se proyecta hacia la comunidad, sin embargo, sí involucra la participación de miembros de comunidad educativa, y miembros de comités de apoyo, para su elaboración mas no para su ejecución. El plan institucional está basado en el marco de la visión, misión y objetivos de cada una de las organizaciones participantes.

El seguimiento al proceso de planificación no es continuo ni monitoreado en su ejecución por parte de la dirección del centro educativo. Sin embargo, se parte de un grado de confianza ante los distintos subcomités para que realicen sus proyectos y se vinculen con la comunidad. La planificación y la vinculación comunal están presentes en las organizaciones educativas. Sin embargo, el proceso de planificación no se proyecta hacia la comunidad.

La gestión de una institución educativa requiere de una planificación efectiva y estratégica que contemple a todos los actores involucrados en el accionar de una organización educativa. Por lo tanto, es deber del director lograr vincular su gestión con la participación de la comunidad en su institución educativa.

La planificación debe ser realizada con la opinión y participación de todos los individuos, para lograr mantener una relación efectiva y eficaz con la comunidad contextual donde se encuentra la organización. Es deber del director involucrar a todos sus miembros de la comunidad educativa para lograr aprovechar no solo recursos internos de la organización sino, también externos que ayuden a una adecuada relación escuela comunidad, como fue el caso del presente estudio, donde se evidencia que este componente merece fortalecerse.

Con respecto al proceso de organización, las instituciones que forman parte del estudio a pesar de que pertenecen a regionales educativas, modalidades y niveles del sistema educativo diferentes, poseen una forma de organización tradicional, similar o igual en todas ellas, que es la conformación de equipos de trabajo, en las que en su mayoría se incorpora al personal. De esta manera se llevan a cabo, una vez detectadas las necesidades, una serie de actividades destinadas a brindar posibles soluciones a esas necesidades. Es el director la figura central en el quehacer de la organización, a este funcionario se le delegan funciones y es a través de 
su gestión que la institución realiza su despliega una serie de directrices a los comités que previamente y producto del conocimiento del personal ha conformado.

En todas las instituciones tienen cierto grado de vinculación con la comunidad, no obstante esa vinculación no es muy trascendental en la ejecución de planes y proyectos que ha propuesto la misma.

Con respecto a la gestión de la institución educativa y su vinculación con la comunidad, en la mayoría de las instituciones ha sido parcialmente efectiva, no como se esperaría por parte de una institución educativa por ejemplo, aunque en algunas hay evidencias de una mejoría, por el hecho de que el número de estudiantes que desertan es menor cada año, el alumnado ha aumentado, las actividades cívicas son notorias y la infraestructura es buena, por lo tanto se satisfacen necesidades comunales importantes.

En relación con al entusiasmo presente o no en el administrador educativo y los miembros de apoyo de la comunidad se encontraron varias maneras en que este se evidencia: trabajo en equipo, interés por la comunidad, interés por la institución, los hijos, los familiares y los nietos son una razón para trabajar y el cumplimiento de proyectos.

Con respecto al proceso de coordinación en las instituciones se considera que brindan una guía de acción para el cumplimiento de los proyectos o planes que articulen el centro educativo con la comunidad. Además, se da autonomía y trabajo en equipo, los cuales son de vital importancia para cada centro educativo.

En cuanto al control, a manera de conclusión, los supervisores, directores, coordinadores académicos y miembros de los equipos de apoyo concluyeron que, dentro de la vinculación del centro educativo con la comunidad, se desea proteger los activos y los pasivos de las instituciones educativas que muchas veces se ven afectadas por agentes que quieren enriquecerse ilícitamente con los recursos del sector público. Se debería de contar con controles más minuciosos en aras del bienestar de las instituciones educativas para llevar a cabo más acciones de control con el fin de verificar que el Plan Operativo Anual se desarrolle con responsabilidad educativa, comunal y por lo tanto social.

Las principales dificultades con respecto a la supervisión del desarrollo de los diferentes programas, proyectos y planes, hace referencia a que los coordinadores académicos son más enfáticos en juzgar este tipo de procedimientos, por ejemplo, para ellos en todas las instituciones, definitivamente las supervisiones no se desarrollan en conjunto con la comunidad; tarea que corresponde llevarla a cabo en conjunto la dirección del centro en conjunto con la supervisión.

En cuanto a las maneras en que se realiza la supervisión del desarrollo de los 
diferentes programas, proyectos y planes, los supervisores de circuito destacan evaluaciones, informes periódicos, vistas institucionales, visitas colegiadas, realización de libros de actas y reuniones. Las acciones que se realizan en las instituciones educativas para el análisis de los resultados de los distintos proyectos, programas o planes las acciones más relevantes encontradas son: sistematización de la información, análisis estadístico, discusiones en reuniones, informes a la supervisión y a la regional y evaluaciones constantes y cualitativas.

Todo proceso evaluativo, en el campo de la administración de la educación, debe tomar en cuenta las creencias propias sobre la materia, las experiencias previas al momento de evaluar, sus juicios de valor y los criterios institucionales, donde se aplique una metodología investigativa y se conozca la propia realidad de la institución y de la comunidad, pero también se reflexiona, se indaga de manera crítica y se autoevalúa comprometidamente.

En general es evidente que producto de los hallazgos generados en el estudio la articulación de la gestión educativa y la comunidad es fundamental en el desarrollo organizacional de toda institución educativa en aras de lograr los fines y objetivos de la educación. No es posible el desarrollo de las instituciones educativas sin la participación activa, democrática y permanente del contexto comunal, este es un componente que influye en forma positiva o negativa en la gestión de la educación, la comunidad es parte de las instituciones educativas y la administración de la educación debe direccionar su quehacer en conjunto con esta articulación centro educativo y comunidad.

\section{Referencias}

Álvarez, I. (2009). Participación y comunidad educativa: contrastes, impedimentos y posibilidades. Revista Pedagogía Universitaria, 3(3), p. 21. Cuba: Editorial Universitaria, Recuperado en: http://site. ebrary.com/lib/uvirtualeducacionsp/Doc?id=10311930\&ppg=

Álvarez, M. (1996). Importancia de los diferentes grupos familiares en la sociedad. San José, Costa Rica: MEP. Recuperado en http://www.educatico.ed.cr/FamiliaComunidad/Importancia\%20de\%20los\%20grupos\%20familiares\%20en\%20la\%20sociedad.pdf

Amar, J. (2000). La función social de la educación. Investigación y Desarrollo, (11), julio, pp. 74 -85. Barranquilla, Colombia: Universidad del Norte. Recuperado en: http://redalyc.uaemex. $\mathrm{mx} / \mathrm{redalyc/src/inicio/ArtPdfRed.jsp?iCve=26801104}$

Avolio, S. (1980). La tarea escolar. Buenos Aires: Ediciones Marymar.

Barrantes, A. (2000). La gestión del centro educativo. Revista Educación. 24(2), pp. 81-95. San José, Costa Rica: UCR. 
Belker, L. y Topchik, G. (2005). Gerente por primera vez. Estados Unidos de América: Grupo Nelson.

Bolaños, B. y Navas, S. (2004). Propuesta de un modelo de evaluación de los materiales didácticos impresos. Innovaciones educativas, 14(9), pp. 27-42. San José, Costa Rica: EUNED.

Buendía, A. y Martínez, A. (2007). Hacia una nueva sociedad del conocimiento: retos y desafíos para la educación virtual. En: Lozano, A. y Burgos, J. (Ed.), Tecnología educativa en un modelo de educación a distancia centrado en la persona, pp. 77-106. México: Limusa. Recuperado en: http://ftp.ruv.itesm.mx/apoyos/logistica/logistica/agosto_dic2009/ege/ ed4022/ed4022_008.pdf

Campos, A. (2011). Análisis del enfoque de evaluación institucional aplicado por la gestión educativa de Costa Rica Christian School. Revista Gestión de la Educación, 2(1). Universidad de Costa Rica: Escuela de Administración Educativa. Recuperado en: http://revistadigital.eae. fcs.ucr.ac.cr/index.php/component/content/article/3/41-analisis-del-enfoque-de-evaluacion-institucional-aplicado-por-la-gestion-educativa-de-costa-rica-christian-school.html

Chacón, A. (2012). La gestión de los conflictos estudiantiles: un enfoque desde la administración de la educación. Revista Gestión de la Educación, 2(1). Recuperado en: http://www. revistadigital.eae.fcs.ucr.ac.cr/images/stories/Vol_2_N.1/La_gestion_de_los_conflictos_ estudiantiles-_Chacon.pdf

Chaves, C. (1996). Planificar para organizar. San José, Costa Rica: Editorial UNED.

Chaves, N. (1996). La Imagen Corporativa. Barcelona, España: Editorial: Gustavo Gili, S. A.

Chiavenato, I. (2003). Introducción a la Administración. México: Mc Graw Hill.

Chiavenato, I. (2004). Introducción a la Teoría General de la Administración. México. Mc. Grall Hill.

Chiavenato, I. (2009). Comportamiento Organizacional. La dinámica del éxito en las organizaciones. México: Mc Graw Hill.

Consejo Nacional de Rectores (CONARE). (2011). Informe del Estado de la Educación. Programa del Estado de la Nación. San José, Costa Rica: Autor. 
Dengo, M. (2000). Educación Costarricense. San José, Costa Rica: Editorial Universidad de Costa Rica.

Dornyei, Z. (2007). Research Methods in Applied Linguistics: Quantitative, Qualitative, and Mixed Methodologies. Oxford, New York: Oxford University Press.

Fernández, T. (2000). Gestión educativa estratégica. Buenos Aires: IIPE. UNESCO.

Freire, P. (1990). Pedagogía de la autonomía. Enseñar es una especificidad humana. Sao Paulo, Brasil: Paz e Terra S.A.

Freire, P. (2004). Pedagogía de la autonomía. Enseñar no es transferir conocimiento. Sao Paulo, Brasil: Paz e Terra S.A.

Gairín, J. y Dander, P. (1994). Organización de centros educativos, aspectos básicos. Barcelona: CISS PRAXIS EDUCACIÓN.

Garbanzo, G. y Orozco, V. (2007). Desafíos del sistema educativo costarricense: Un nuevo paradigma de la administración de la educación. Revista Educación, 31(2), pp. 95-110. San José, Costa Rica: Universidad de Costa Rica.

Garbanzo, G. y Orozco, V. (2010). Liderazgo para una gestión moderna de procesos educativos. Revista Educación, 34(1), pp. 15-29. San José, Costa Rica: Universidad de Costa Rica.

Garbanzo, G. (2011). Condiciones dignas de la labor docente del siglo XXI, un derecho inalienable, no una opción. Revista Electrónica Educare, 2(14), pp. 87-109. Centro de Investigación y Docencia en Educación (CIDE): Universidad Nacional. Recuperado en: http://www.revistas.una.ac.cr/index.php/EDUCARE/article/view/1961

García, N.; Rojas, M. y Campos, N. (2002). La administración escolar para el cambio y el mejoramiento de las instituciones educativas. San José, Costra Rica: EUCR.

Gento, S. (2008). Gestión y supervisión de centros educativos. San José, Costa Rica: EUNED.

González, M. (Coordinadora). (2003). Organización y gestión de centros escolares: dimensiones y procesos. Madrid: PEARSON EDUCACIÓN.

Gurdián, A. (Compiladora). (2000). Una mirada crítica a la educación. San José, Costa Rica: EUCR. 
Hopenhayn, M. (2002). Educar para la sociedad de la información y de la comunicación: una perspectiva latinoamericana. Revista Iberoamericana de Educación, (30). Organización de Estados Iberoamericanos (OEI Ediciones). Recuperado en: http://www.rieoei.org/rie30a07. htm

Ley Fundamental de Educación. (2003). San José: Editorial Investigaciones Jurídicas S.A.

Martín, M. (2002). Planificación de centros educativos: organización y calidad. Barcelona: Cisspraxis.

Medina, J. (2011). La colaboración entre escuela y comunidad: perspectiva de directores escolares. (Disertación presentada como requisito para la obtención del grado de Doctor en Educación). Escuela de Educación. Universidad del Turabo, Puerto Rico. Recuperado en: http://udini.proquest.com/view/la-colaboracion-entre-escuela-y-pqid:2506717471/

Ministerio de Educación Pública (MEP). (2011). Normas de promoción y repitencia del reglamento de evaluación de aprendizajes. Recuperado en: http://www.mep.go.cr/downloads/despacho/ NORMAS\%20DE\%20REPITENCIA.pdf

Meza, G. (1999). Educación. Cartago, Costa Rica: Taller de Publicaciones del Instituto Tecnológico de Costa Rica.

Mora, J. y Solano, M. (2005). Integración de los Miembros de la Comunidad Educativa de la Escuela La Alegría de Orosi en el Fortalecimiento del Desarrollo Escolar. (Proyecto de graduación presentado ante La Escuela de Administración Educativa al grado de Licenciatura en Ciencias de la Educación con énfasis en Administración Educativa). Universidad de Costa Rica. Escuela de Administración Educativa. Ciudad Universitaria Rodrigo Facio Brenes. San José, Costa Rica.

Morales, N. (2004). El hecho educativo como hecho social. Innovaciones educativas, 14(9), San José, Costa Rica: EUNED.

Munich, L. y García, J. (1986). Fundamentos de administración. México: Trillas.

Ordóñez, C. (2002). Administración y desarrollo de comunidades educativas. Hacia un nuevo paradigmas de organización escolar. Colombia: Editorial Magisterio.

Paciano, F.; Cappella, J. y Collom, A. (2005). Teoría de la educación. San José, Costa Rica: EUNED.

Pozner, P. (2000). Gestión educativa estratégica. (Módulo 2 de la serie). Buenos Aires, Argentina: IIPE/UNESCO. 
Robbins, S. y Coulter, M. (2000). Administración. México: PRENTICE HALL.

Stoner, J.; Freeman, E. y Gilbert, D. (1996). Administración. México: PRENTICE HALL.

Tejada, J. (2000). La educación en el marco de una sociedad global: algunos principios y nuevas exigencias. Profesorado: Revista de Currículum y Formación de Profesorado, 4(1), pp. 1-13. España: Universidad de Granada. Recuperado en: http://redalyc.uaemex.mx/redalyc/src/inicio/ArtPdfRed. jsp?iCve $=56740102$

Venegas, P. (2000). Hacia la modernización de la administración educativa costarricense. San José, Costa Rica: Ministerio de Educación.

Venegas, P. (2011). Gestión de la educación basada en competencias: elementos para su interpretación en el contexto de la Administración de la Educación. Revista Gestión de la Educación, 1(1). San José, Costa Rica: UCR. Recuperado en: http://www.revistadigital.eae.fcs.ucr. ac.cr/images/stories/edicion_1/DOCS/Gestion\%20de\%20la\%20Educaci\%C3\%B3n\%20 basada\%20en\%20competencias.pdf 